\title{
Applying the Analytic Hierarchy Process in healthcare research: A systematic literature review and evaluation of reporting
}

\author{
Katharina Schmidt ${ }^{1 *}$, Ines Aumann ${ }^{1}$, Ines Hollander ${ }^{2}$, Kathrin Damm ${ }^{1}$ and J.-Matthias Graf von der Schulenburg ${ }^{1}$
}

\begin{abstract}
Background: The Analytic Hierarchy Process (AHP), developed by Saaty in the late 1970s, is one of the methods for multi-criteria decision making. The AHP disaggregates a complex decision problem into different hierarchical levels. The weight for each criterion and alternative are judged in pairwise comparisons and priorities are calculated by the Eigenvector method. The slowly increasing application of the AHP was the motivation for this study to explore the current state of its methodology in the healthcare context.

Methods: A systematic literature review was conducted by searching the Pubmed and Web of Science databases for articles with the following keywords in their titles or abstracts: "Analytic Hierarchy Process," "Analytical Hierarchy Process," "multi-criteria decision analysis," "multiple criteria decision," "stated preference," and "pairwise comparison." In addition, we developed reporting criteria to indicate whether the authors reported important aspects and evaluated the resulting studies' reporting.
\end{abstract}

Results: The systematic review resulted in 121 articles. The number of studies applying AHP has increased since 2005. Most studies were from Asia (almost $30 \%$ ), followed by the US (25.6\%). On average, the studies used 19.64 criteria throughout their hierarchical levels. Furthermore, we restricted a detailed analysis to those articles published within the last 5 years $(n=69)$. The mean of participants in these studies were 109, whereas we identified major differences in how the surveys were conducted. The evaluation of reporting showed that the mean of reported elements was about 6.75 out of 10. Thus, 12 out of 69 studies reported less than half of the criteria.

Conclusion: The AHP has been applied inconsistently in healthcare research. A minority of studies described all the relevant aspects. Thus, the statements in this review may be biased, as they are restricted to the information available in the papers. Hence, further research is required to discover who should be interviewed and how, how inconsistent answers should be dealt with, and how the outcome and stability of the results should be presented. In addition, we need new insights to determine which target group can best handle the challenges of the AHP.

Keywords: Multi-criteria decision making, Priorities, Analytic Hierarchy Process, Methodological standards, Systematic literature review

\footnotetext{
* Correspondence: ks@cherh.de

${ }^{1}$ Center for Health Economics Research Hannover (CHERH), Leibniz University

of Hanover, Otto-Brenner-Str. 1, 30159 Hannover, Germany

Full list of author information is available at the end of the article
} 


\section{Background}

The resources in health care systems are limited. Exacerbating this issue is the problem that many developed countries face, that is, the rising proportion of older, multimorbid patients, who serve to raise the cost of health care. Furthermore, innovations in medical care, such as equipment, pharmaceuticals, and treatment methods, are also driving up costs. German politicians have adopted new laws to manage the costs of pharmaceuticals, e.g. the Act on the Reform of the Market for Medicinal Products in 2011 (in German: AMNOG [1]). In this context, patient-relevant outcomes have drawn greater attention because the added benefit for patients determines the reimbursement price. But also, other countries are interested in reliable methods to measure benefits for patients, for example, to support Health Technology Assessments by patient preferences $[2,3]$. Therefore, while it is now important to measure the benefits and to prioritize the needs of patients, it will be even more so in the future. However, several studies have found a divergence in patients' and physicians' preferences or priorities regarding prevention and therapy (e.g. [4-6]). Thus, one mean of evaluating these preferences and bringing them into accord is to take the required perspective for the situation. In order to find appropriate methods for measuring the benefits and for prioritizing them, beside the established methods, new approaches of decision making tools are transferred from other fields of research, like the marketing sector. For all of these methods it is essential to measure the trade-off between attributes in multi-criteria decision situations for each participant or the group, and as such, adequate and understandable methods are essential.

Several methods are known for multi-criteria decision making in the field of health care, including value based methods, strategy based methods, and conjoint analyses [7]. In Germany, the Institute for Quality and Efficiency in Health Care (IQWiG) suggested two methods for multiattribute decision making: Conjoint Analysis (CA) and the Analytic Hierarchy Process (AHP) [8]. Although they concluded that both methods are applicable for decision making, they were also confronted with methodological limitations. As the advantages and disadvantages of established methods like the CA have been discussed in a number of publications (e.g. [9-11]), the AHP method has received less attention. Therefore, we wanted to figure out whether the AHP method could become a good alternative in multi-criteria decision making.

\section{Relevance and objective of the study}

The Analytic Hierarchy Process (AHP) was developed by Saaty in the late 1970 s and originally was applied to the marketing sector $[12,13]$. Dolan et al. were the first to apply this method to health economics research in 1989 $[14,15]$; since then, it has been accepted slowly as a method in the field of multi-criteria decision making in healthcare. Liberatore and Nydick described the importance of applying the AHP as follows: "Health care and medical decision making has been an early and on-going application area for the AHP" [16]. The AHP method was applied to different contexts, for example, the development of clinical guidelines $[17,18]$ or biomedical innovations and technology development $[19,20]$.

The increasing application of the AHP has been the motivation for this study to explore the current state of its methodology. The method is the basis for assessing the best instrument for each decision situation and reflecting each participant's opinion correctly. A review provides an overview of published papers in this field. In line with De Bekker-Grob et al. [21], we provide a systematic review of the AHP. Therefore, an overview is given of the year of publication, country, and number of criteria used in the AHP (Section 3). In addition, Hummel and Ijzerman [22] analyzed the thematic field in which AHP is used. They identified the different areas of application (e.g., shared decision making, clinical guidelines, and healthcare management), number of criteria and alternatives, individual or group decisions, participants, and rating method. We focus on the methodological applications in the second step. In addition, the analyzed time horizon (2010-2015) should provide an update on Hummel and Ijzerman's study and allow us to provide details of the most recent developments in the subject area. As in Mühlbacher's overview [23], the field of application and the sample are inspected, although our focus remains on the current state of the research (the last 5 years) and the reporting of methodological aspects in the papers. In addition, the evaluation of studies' reporting allows deeper insights. Therefore, we develop criteria for reporting the AHP method and determine to what extent the studies fulfill the criteria. We conclude by proposing recommended situations in which the AHP can be used.

\section{AHP - a short introduction}

As a short introduction into the method of AHP, we report the most important aspects here. We refer to detailed papers to provide deeper insights into specific methodological aspects.

The AHP disaggregates a complex decision problem into different hierarchical levels (see Saaty's axioms for the AHP [24]). The application of an AHP is structured into six steps (see also Fig. 1), suggested by Dolan et al. [25] and Dolan [7], as follows: 1. define the decision goal, criteria, and alternatives, 2 . rate the criteria in pairwise comparisons, 3. calculate the relative priority weights for the (sub-)criteria, 4. calculate the criteria's global priority weights and combine the alternatives' priorities, 5 . control for inconsistency, and 6. perform sensitivity analysis. 


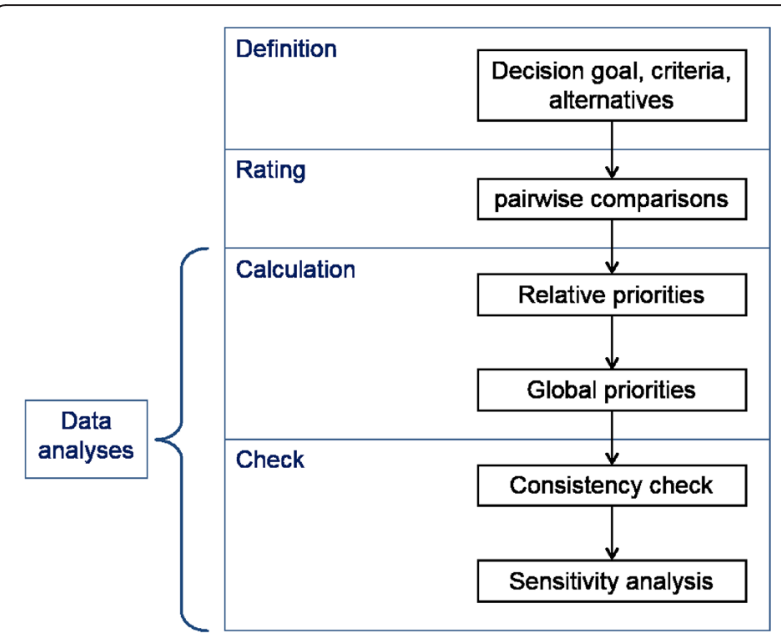

Fig. 1 Steps of the AHP (modeled after Dolan et al. [25] and Dolan [7]])

At the first hierarchical level, the aim of the study is defined followed by the main criteria, which can be divided further at lower levels into sub-criteria. If necessary, alternatives that contain specific combinations of characteristics can be arranged at the lowest level of the hierarchy. Although the AHP was introduced for group decisions, it may also be applied to single person decisions [26]. Pairwise comparisons at each hierarchical level present the judgments and they must be evaluated according to a scale developed by Saaty, which ranges from 9 to 1 to 9 . If the alternatives consisted of subjective combinations of the criteria, the alternatives would be judged also with regard to each criterion. Saaty provided a detailed description of his scale and its intensities [12].

In order to analyze the interviews, the pairwise comparisons of (sub-)criteria at each level are displayed in ordered schemes (matrixes). An example is seen in Saaty ([24], p. 164). Only half of the matrix has to be filled in, as the other half is obtained from the reciprocal weights. The Eigenvector method $(\mathrm{EV})$ is the most common means of calculating the priority vector, although other methods, such as additive normalization, weighted least-squares, logarithmic least-squares, logarithmic goal programming, and fuzzy preference programming methods, yield comparable results [27]. The EV relies on the matrix's principle eigenvalue, which results from a process of repeated squaring and normalization (for more information, see Srdjevic [27] or Saaty [12]). The resulting local weights describe the relative priorities in relation to their parent criterion. The local weights form the global weights for the criteria through multiplication with the local weights from their parent criteria [24]. Thereby, global weights for criteria show the importance of each criterion in the overall context of the hierarchy. The priorities for the alternatives of the AHP are calculated by the sum of the particular local and global weights for each alternative [23]. For detailed information and examples concerning the calculations, see Saaty [28].

The aggregation of the individual judgments or priorities is fundamental to the outcome of the study. The first option is to have the group of participants vote by finding consensus. Another alternative is to aggregate the individual judgments. Still further, the literature suggests finding the geometric mean [29] or arithmetic mean [30]. In addition, the timing of calculating the average affects the results [30], specifically, the average of participants' judgments or the average of participants' global weights. Yet another option is to give special weight to one participant's decision on the basis of that participant being an expert in the field or holding an exceptional position within the group [30]. The consistency ratio (CR) measures the uniformity of a respondent's answers to the AHP questions. Saaty [24] describes the calculation of the CR in detail. The $\mathrm{CR}$ can also be calculated for a group of respondents.

Although the AHP has been applied to a variety of topics within the healthcare field, the sensitivity analyses on hierarchical decision making has received little investigation [31]. It should be noted that there are two distinct types of sensitivity analysis, that of judgments and that of priorities [32]. The former has been explained and tested by Arbel [33], Moreno-Jimenez and Vargas [34], and Sugihara and Tanaka [35]. They determined the judgments' upper and lower bounds and articulated the preferences through preference structures. Other approaches originate from Moreno-Jimenez and Vargas [34], Triantaphyllou and Sánchez [36], Sowlati et al. [37], Masuda [38], and Huang [39]. Erkut and Tarimcilar [40] provided "a collection of practical tools for a potentially powerful sensitivity analysis in the AHP". In addition, Altuzarra et al. [41] proposed a method for determining the stability of group decisions. If the AHP includes alternatives, the sensitivity analysis could show the effect of varying weights on the alternatives' rankings [23]. Therefore, potential rank reversal of alternatives can be simulated. Rank reversal occurs when adding or deleting an (irrelevant) alternative leads to a shift in the previous alternatives' ranking order [42].

\section{Methods}

This chapter is divided into two parts to introduce the methods used in this paper. The first part describes the method of the systematic review, which includes the key words and a flow chart. Further, in chapter 2.2, we describe our evaluation of reporting quality for the included studies.

\section{Systematic literature review}

The basis of this review is a systematic literature research on the Pubmed and Web of Science databases (date of research: 10/27/2015). As we focused our research question 
on healthcare, we did not include further databases in the other scientific fields. We searched both databases for articles with the following keywords in their titles or abstracts: "Analytic Hierarchy Process," "Analytical Hierarchy Process," "multi-criteria decision analysis," "multiple criteria decision," "stated preference," and "pairwise comparison." We provided the search strategy in Appendix: Table 1. It was technically not possible to search Web of Science for keywords in the abstracts. We refined the search by including only articles written in German or English and those associated with healthcare. Two independent reviewers evaluated the titles and abstracts of the resulting studies. Therefore, the criterion for inclusion was that the article is the primary source and the study used the AHP method within the healthcare setting. Additionally, we conducted a manual search to find further articles not included in the aforementioned databases. Thereafter, the two reviewers screened the full texts of the remaining articles and discussed whether to include them in the review. After reaching consensus, the important information was summarized in a table (not shown). Apart from common information, like the author, title, publication year, country, and journal, we extracted additional information regarding the study's aim, source of criteria identification, hierarchy design, form of implementation, and analytical steps in order to conduct our analysis. The results are described in Section 3 for the entire period and in detail for the last 5 years in Subsection 3.1. The first step should give a short overview of all studies that were conducted with AHP in health care. In the second step, we reported the current state of research in more detail.

\section{Evaluation of reporting quality}

The papers identified from the last 5 years resulting from the systematic review were evaluated with regard to their reporting quality. Because there was no set standard by which to judge the AHP's methodological issues, the evaluation of the studies' quality was quite challenging. The before mentioned studies by De Bekker-Grob et al. [21], Hummel and Ijzerman [22], and Mühlbacher et al. [23] did not report quality criteria. However, the Consolidated Standards of Reporting Trials (CONSORT) Statement for randomized controlled trials [43] and the Preferred Reporting Items for Systematic Reviews and Meta-Analyses (PRISMA) Statement [44] may provide some direction by providing checklists for transparent and complete reporting. The reason why authors should report specific aspects is the traceability of the study. Some criteria from the CONSORT Statement could be transferred to AHP studies: sample size, participants (eligibility criteria), trial designs, and statistical methods. In the case of the AHP method, the latter criterion consists of the CR, the method used to calculate the weights, the statistical software, and sensitivity analyses. Another checklist item is the description of the intervention. Transferred to the AHP method, authors should provide information about the interview process. Besides, another guideline for good research practices is published by Bridges et al. [9]. They provide a detailed checklist that is specific for conducting conjoint analyses. Since it suggests quality aspects only for those kinds of studies, the checklist cannot be used directly for our evaluation. However, we summarized the recommendations from the different fields and we obtained a simplified measurement of reporting by counting the elements that were included in the studies. Therefore, we evaluated whether the authors mentioned aspects for the following elements in their papers:

- Decision goal, criteria (and if necessary alternatives)

- Number of participants

- Type of participants (patients, potential consumers, or experts)

- Decision making by group or individually

- Scale for pairwise comparisons

- Interview process (face to face, email, questionnaire, judgments based on literature)

- Software

- $\mathrm{CR}$

- Calculation of weights

- Sensitivity analysis

The last criterion was valid only for studies including alternatives. Thus, for the other papers without alternatives, we could determine only whether descriptive statistics (e.g., standard deviation, SD and confidence intervals, CI) were reported for the judgments or weights. We calculated the sum of all reported aspects for each study and present the results in Appendix: Table 2 and we show charts in Subsection 3.2. Nevertheless, we could not evaluate the content of each of the abovementioned criteria but only whether the criteria were reported in the study.

\section{Results}

The search in Pubmed yielded to 1,956 articles and the search in Web of Science yielded to 4,829 articles, as Fig. 2 shows. Furthermore, 44 additional records were found via manual search. By screening titles and abstracts, we limited the sample to 246 articles (we excluded a total of 6,485 articles based on language or irrelevance to healthcare and we found 54 duplicates). Thereafter, we examined the full articles in order to determine whether they apply AHP to the field of healthcare. An additional 125 papers were excluded because they were not original studies or they used other stated preference methods (e.g., discrete choice experiment). In total, this process yielded to 121 relevant studies; the Appendix: Table 3 provides a complete list. We provide a brief overview of these studies to show how many studies have been published in this 


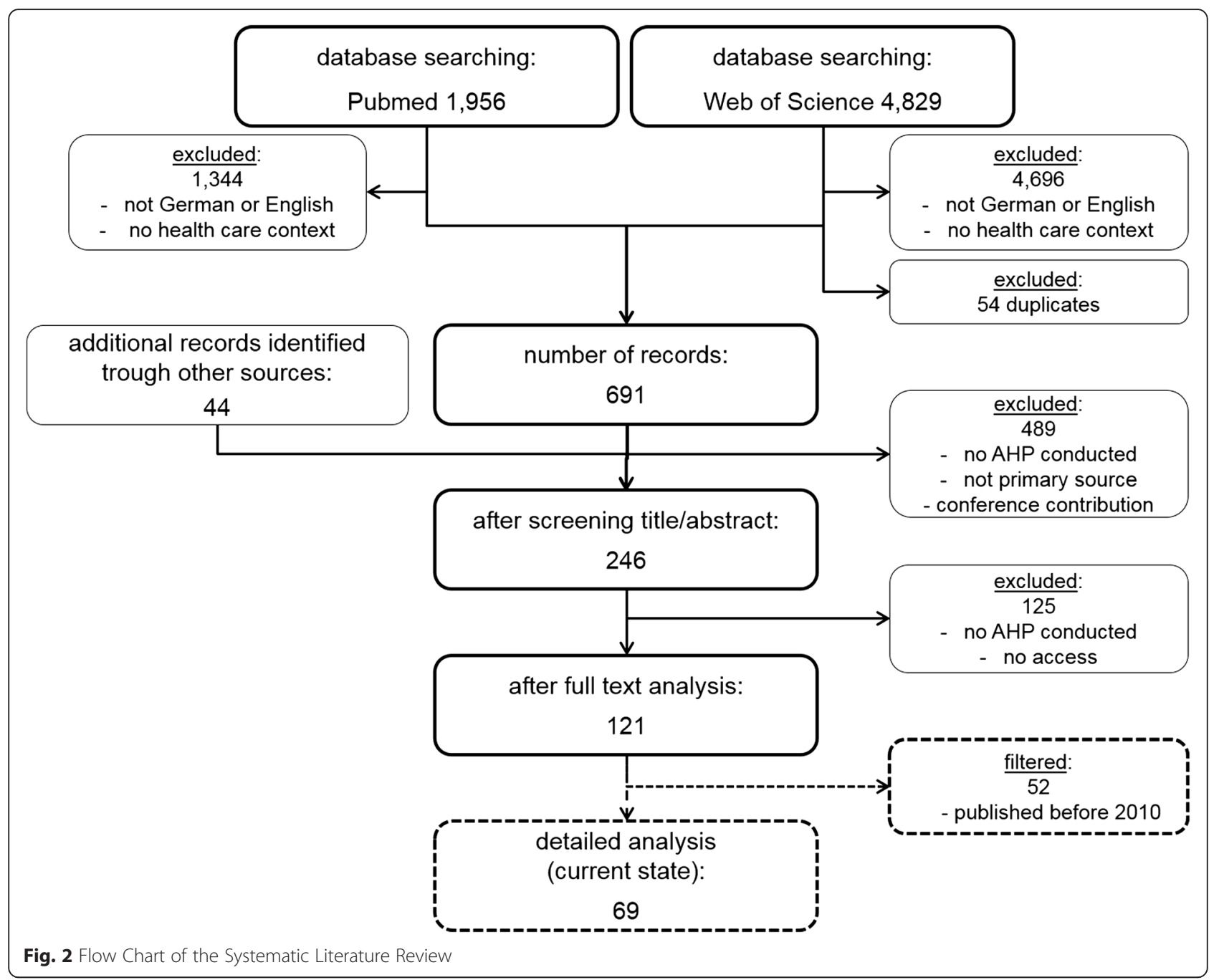

field and in which context the authors used the AHP. In addition, the overview presents the development and the relevance to the AHP method. In order to explore the current state of the literature, we limited the body of our research to articles published within the last 5 years. This restriction reduced the number of studies to 69 . The detailed analysis of these studies' methodologies made it necessary to reduce the number of articles.

For a first overview, we briefly summarized the key factors of all of the relevant articles $(n=121)$, such as their publication year, country, number of attributes, and levels.

The earliest study to use the AHP was published in 1981, but the AHP has become increasingly popular since 2005 (see also Fig. 3). The 2 years with the greatest number of studies published on the subject were 2011 and 2012 with nine each. However, it should be noted that our evaluation period contains only the first 10 months of 2015, in which as many as 20 studies were published. On average, there were 2.5 studies per year between 1981 and 2013 . During the 1990s, there was an average of 1.7 publications on the AHP per year, which increased to 4.6 per year between 2000 and 2013. In 2014 and 2015 the average increased to the peak of 18.5 studies, although the last two months of 2015 are not included.

Most studies were from Asia (29.75\%), followed by the US (25.62\%). Almost all studies published before 2000 were conducted in the US $(n=15)$. However, between 2000 and 2010, a larger proportion came from Asia $(n=8)$ and Europe $(n=7)$, although most were still from the US $(n=8)$. Since 2010, Asia $(n=26)$ and Europe $(n=17)$ have surpassed the number of publications in the US $(n=8)$.

Another important aspect of these studies is the number of hierarchical levels that they include. Therefore, the studies could include more than one hierarchy, so in some cases the number of studies did not sum up to 121. More than half of the studies $(51 \%)$ included three hierarchical levels, $23 \%$ described their hierarchy with two levels, and $21 \%$ used four levels. On average, the studies used 19.76 criteria throughout their hierarchal levels. At the second hierarchical level, 96 articles (78 \%) 


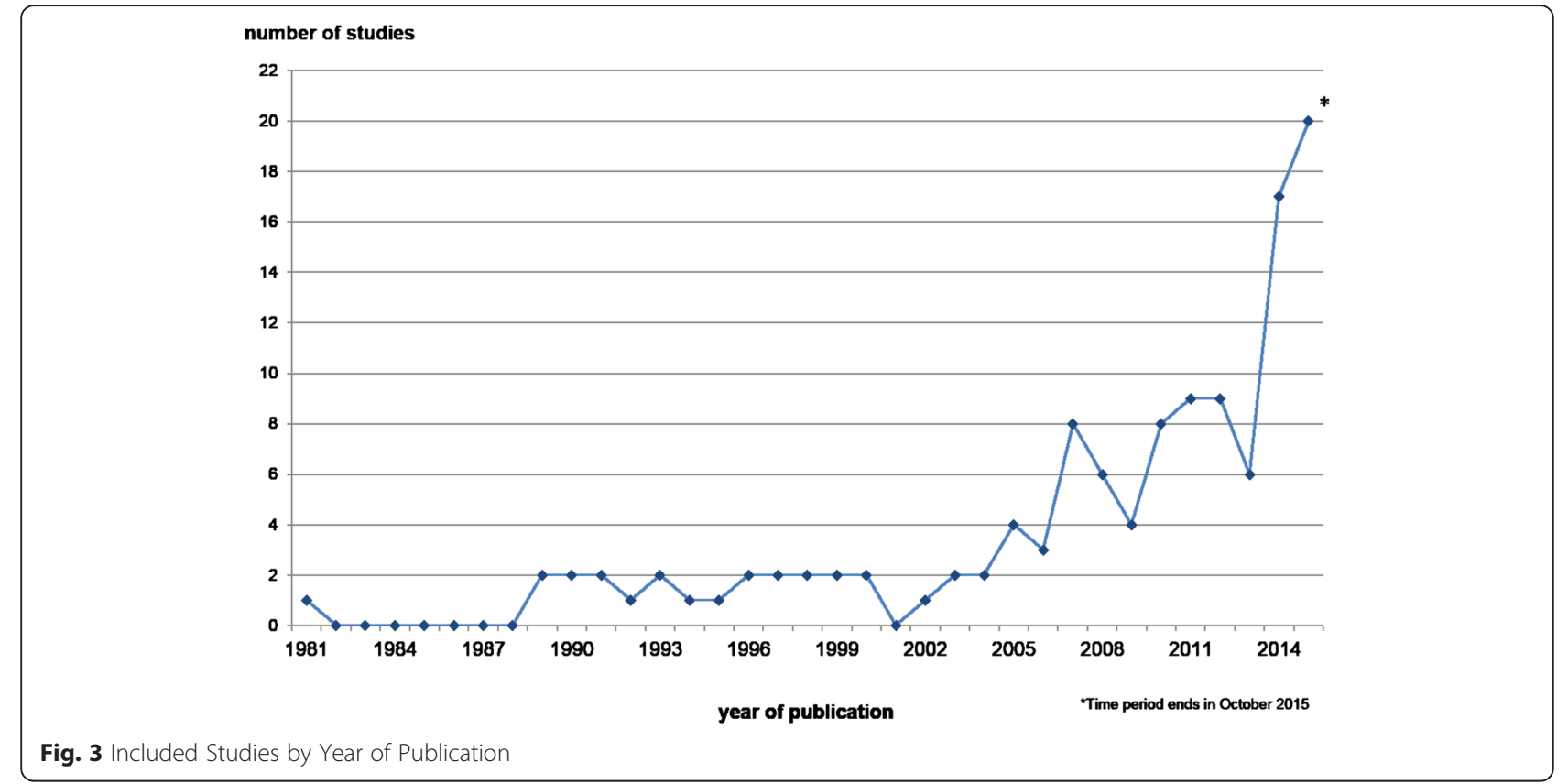

included between 1 and 5 criteria (Fig. 4). At the third and fourth levels, most studies $(n=39$ and $n=16$ or 45 and $47 \%$, respectively) used between 11 and 20 criteria. The number of studies with five hierarchical levels was quite small $(n=3)$. As expected, the number of criteria increases as the hierarchical level increases. The right bar in Fig. 4 shows the total number of criteria for all hierarchical levels per study.

Following the method set forth by Hummel and Ijzerman [22], we divided the studies into five categories: development of clinical guidelines, healthcare management, government policy, shared decision making, and biomedical

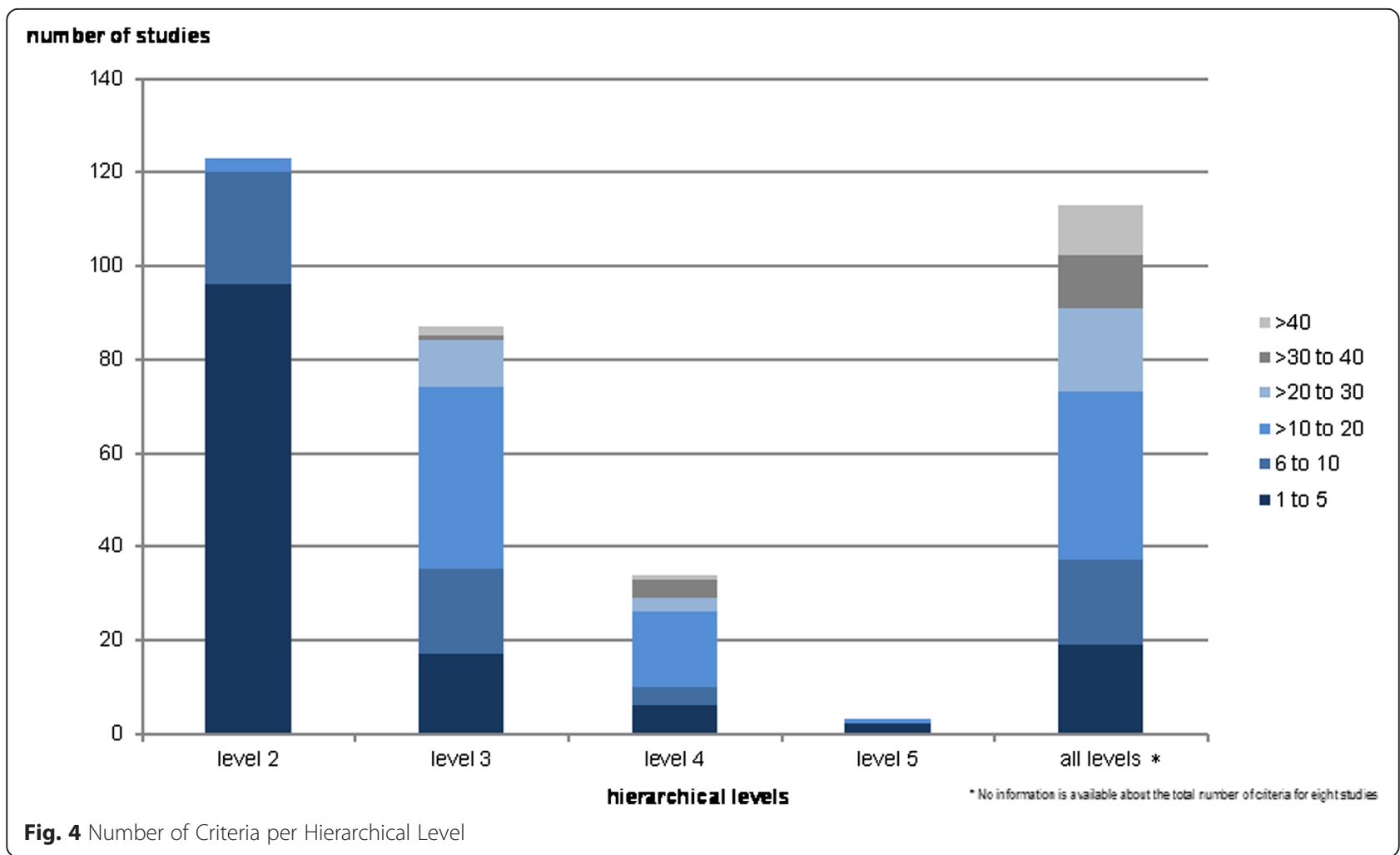


innovation. We classified 38 studies (31\%) as pertaining to the development of clinical guidelines or recommendations, $30(25 \%)$ to healthcare management, 26 (21\%) to government policy, 15 (12\%) to biomedical innovation, and12 $(10 \%)$ to shared decision making.

\section{Detailed analysis of the current state of research}

This subsection summarizes the results of our analyses of the articles published within the last 5 years (January 2010 to October 2015). We examine how the studies design their hierarchies and carry out their surveys, and which analytical steps they take. In doing so, we follow the steps for conducting an AHP shown in Fig. 1.

\section{Definition of decision goal, criteria, and alternatives}

The first step in conducting an AHP is to define the decision goal and criteria that describe the goal at a lower hierarchical level. In order to do this, many studies relied on literature research $[20,25,26,45-83]$. In addition, many studies relied on expert interviews [20, $45-49,51,54,56-58,61,66-71,74,75,77,78,81-97]$ or focus groups $[26,51,69,82,87,98]$. Almost all of the studies defined their criteria by analyzing more than one source of information, although five publications did not explain their process for this step [99-103]. Some authors defined the criteria according to standards or established guidelines $[25,50,52,59,80,84,92,93$, $104-108]$ or even from previous study results $[25,47$, $62,68,69,71,72,81]$. Still other authors relied on their own expertise $[64,73,107,109,110]$.

\section{Judgment through pairwise comparisons}

The sample sizes varied between one author who judged the AHP for himself [73,107-109] to 1,283 participants [55]. In total, 50 of the 69 articles reported the number of participants in their AHP studies. The mean number of participants in these studies was about 109. Depending on the studies' goal, the participants belonged to the following groups: hospital employees [49, 92], patients [25, 47, 55, $59,60,64,69,72,75,82,95,98]$, public/consumers [52, $70,103]$, doctors or specialists $[26,71,72,74,79,81,83$, $93,94,96,97,99,110]$, medical students [80] or teachers [77], biomedical engineers [94], technical experts [93], managers [93], administrators [20], and stakeholders [75]. Of the studies, 44 interviewed experts $[20,26,45,46,48-$ $51,54,56-58,61,62,66-68,71,74,76-79,81,83-94,96$, $97,99,104-107,110], 11$ studies surveyed consumers or patients $[25,47,52,55,59,60,69,70,82,98,103]$, and four studies included both [64, 72, 75, 95]. However, six authors did not mention who answered the AHP questions [53, 63, 65, 100-102].

Next, we considered whether the AHP was applied at individual or group level. Most of the studies questioned their participants individually $[20,25,26,47,55,56,59$,
$61,62,64,66,69-71,74,75,77,79-83,87-90,94,97-$ $99,103,104,109-111]$. On the other hand, only six articles mentioned group decisions [46, 49, 72, 84, 92, 96]. Five studies conducted individual judgments as well as group decisions [51, 60, 86, 93, 95]. The remaining 23 articles did not describe the judgment, or they had only one person who answered.

In addition, there were differences in the applied scales for the pairwise comparisons. As explained in Subsection 1.1, the original scale implemented by Saaty ranges from nine (or 1/9) to one to nine. This scale was adopted by 37 of the articles in our sample $[25,45,46$, 50-52, 54-57, 60-62, 66, 71-73, 75, 79, 80, 83, 84, 86$89,91,92,94,95,97,98,102,103,107-109,111]$. Other studies used ranges between 1 and 4 [20,59], 1 and 5 [67, 70, 106], 5 and 1 and $5[26,81,90,110], 6$ and 1 and 6 [99],1 and 7 [47],1 and 9 [58, 77, 96], and 1 and 11 [74]. The remainder of the studies did not provide information about their scale $[48,49,53,63-65,68,69$, $76,78,82,85,93,104]$.

Furthermore, there were major differences in how the surveys were conducted. Once again, not all of the authors discussed their process in detail, but those that did so used online questionnaires $[20,47,51,55,58,70,74$, $75,81-83,111]$ (emailed) questionnaires $[26,59,64,66$, $71,77,79,80,86,91,94,95,104,110]$, face-to-face interviews $[25,45,87,90,98]$, group discussions or workshops $[49,60,64,72,84,86,92,93,96]$, or Delphi panel method [61].

\section{Analysis and validation of results}

Specific software can support the AHP design and further analyses. However, only 35 of the 69 studies $(49.28 \%)$ mentioned which software they used. The majority of the studies that reported software chose Expert Choice ${ }^{\circ}(23.19 \%)$, while others used such packages as Microsoft Excel [25, 77, $88,90]$, or IBM SPSS Statistics [45, 53, 80, 99, 104]. In the last 5 years, a more diverse range of software packages has been in use; in addition to the aforementioned packages, researchers have chosen Super Decisions TM or Crystal Xcelsius [73, 107], or programmed their own software [20].

The detailed analysis showed that 22 out of the 69 studies did not state a CR. However, 31 studies used a CR of $0.1[20,26,45,46,49-51,56,57,60-62,67,71-$ $74,76,77,83,87,89,91,98-102,107-109]$, five studies widened the range to a $\mathrm{CR}$ of $0.15[25,59,64,75,111]$, and three studies accepted a CR of 0.2 or less [70, 81 , 97]. The remaining studies did not establish a threshold prior to measuring average CRs $[55,80]$. As a consequence of these consistency conditions, 14 of the studies reported the number of participants that must be excluded in order to meet their established threshold $[47,55,59,61,63,70-72,75,78,81,98,99,104]$. However, only a small proportion of the studies actually 
outlined a procedure for dealing with excessive inconsistency (i.e., a CR above the established threshold). Chen et al. [70] and Pecchia et al. [26] asked the participants to fill out their questionnaires again. Hummel et al. [94], Suner et al. [83], Velmurugan et al. [102], and Cancela et al. [51] asked the participants to check and revise their decisions. Chung et al. [71], Li et al. [77], and Pecchia et al. [81] excluded the inconsistent participants from their analyses. Hou et al. [67] wrote that, in this case, "the judgment matrix has to be modified and recalculated." Page et al. [80] ran simulations in which they assumed that the inconsistent answers were, in fact, consistent in the first place.

Furthermore, we examined group decision making. Danner et al. [72], Lin et al. [91], Papadopoulos et al. [56], Reddy et al. [86], Shojaei et al. [87], Jaberidoost et al. [66], and Hsu et al. [90] explored this topic by taking the geometric mean of the individual weights. Hilgerink et al. [93] and Hummel et al. [94] summarized the individual judgments with geometric means, and then, calculated the group weights. Conversely, other studies only averaged the group judgments [75, 95]. Olivieri et al. [79] presented two AHPs; in the first, they calculated geometric means for the ranks and in the second, they calculated the interparticipant, standardized, geometric means of the weights as well as the inter-participant means. Perseghin et al. [96], Uzoka et al. [97], and Kuruoglu et al. [98] aggregated the participants' judgments according to the median, and then, calculated the weights. By contrast, Taghipour et al. [49] constructed the group judgments by using weighted means. Unfortunately, 40 of the studies did not describe their weight calculations in detail $[20,45-48,50-55$, 57, 58, 61-65, 67-70, 73, 74, 77-79, 82, 85, 88, 89, 96, 99-101, 103, 104, 106, 107, 110]. However, 39 authors mentioned that they used the EV $[25,26,45-47,49,50$, $55-57,59,60,62,65,66,71,72,75,76,80,81,83,86-$ $95,97,100,102,104,105,108,109]$.

Very few of the studies $(n=14)$ examined the robustness of the weights $[46,53,56,73,76,78,80,82,86$, 93, 100, 101, 105, 107]. Diaz-Ledezma et al. [107] and Diaz-Ledezma and Parvizi [73] referred to Erkut and Tarimcilar [40], who introduced sensitivity analysis for the AHP. Hilgerink et al. [93] factored in uncertainty regarding the included criteria by asking participants to rate the sensitivity and specificity of the pairwise judgments on a three-point scale; this yielded negative, average, and positive scenarios for the overall priorities. The other studies did not mention efforts to account for uncertainty. Further studies conducted their sensitivity analyses with the graphics provided in Expert Choice $^{\bullet}[100,101]$.

This subsection presents the most relevant aspects of conducting AHP, and thereby, reveals a high proportion of missing information from the literature. However, we summarize these facts in Subsection 3.2 and evaluate the number of reported aspects.

\section{Evaluation of reporting}

In a final step, we evaluated the reporting of the studies (see Subsection 2.2). Therefore, we suggested ten criteria that the authors should address in their articles. Most of the aspects are described in Subsection 3.1, and so, we focus on the number of reported elements for evaluating the studies in this section. We evaluated the studies published between 2010 and 2015 (until the 27th of October) and the detailed table can be found in Appendix: Table 1 . In addition, we summarized the most important aspects from the table in the following graphs.

Figure 5 shows that all of the studies $(n=69)$ reported their decision goal and their criteria in their publications. However, several studies did not describe their interview process and did not mention which software they used. Particularly, only 15 out of 69 studies reported that they conducted sensitivity analysis.

The minimum number of reported criteria is one, namely, the study of Hsu et al. [63]. They described the aim of the study (assessment of oral phosphodiesterase type 5 inhibitors for treatment decisions of erectile dysfunction) and the hierarchy for the AHP but said nothing about the methods or study process. The studies that reported the highest number of ten criteria were published by Page [80] and Maruthur et al. [111]. The mean of the reported elements is 6.75 , whereas only 12 out of 69 studies $(17.39 \%)$ reported less than half of the criteria.

The next figure demonstrates the results from our evaluation of reporting quality (Fig. 6). This figure shows the results from our evaluation regarding the reporting quality of all publications between 2010 and 2015. The highest number of studies reached seven or eight points in the evaluation. Only a small number of studies $(n=2)$ reported one or two aspects required. However, two publications also reported all of the criteria. The mean of reported criteria is 6.75 .

Furthermore, we divided the publications into two time periods because we wanted to examine whether the reporting quality has changed (not shown graphically). Therefore, we took the studies published between 2010 and 2013 and compared them with the recent state of research since 2014 (the peak of published studies seen in Fig. 3). In the last 2 years, five studies got nine points in comparison to only three studies in the early time period. Indeed, two publications from the last 2 years only reached one or two points compared to no publications between 2010 and 2013. As the mean of the reported criteria is 6.88 for the early period and 6.65 for the last 2 years. Apparently we do not see the expected increase of reporting quality. 


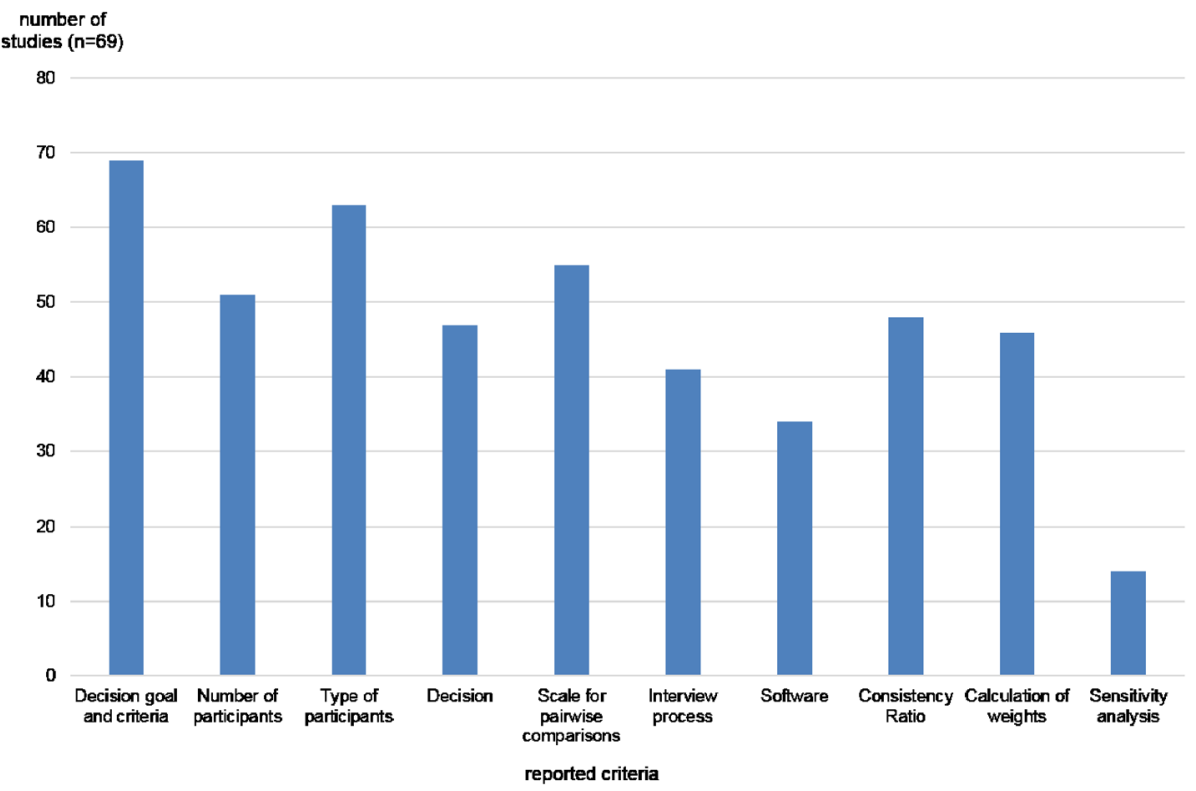

Fig. 5 Number of Studies by the Reported Criteria

\section{Discussion}

As seen from the review, in the last 10 years (and particularly in the last 2 years), there has been a clear upward trend in the number of publications that apply the AHP to healthcare. One reason for this could be the increasing acceptance and the discussion about integration of this method into policy decision processes. For example, the IQWiG in Germany suggests the AHP in decision making regarding reimbursement as one appropriate method [8]. Currently, the development of clinical guidelines is the most popular subject for AHP studies, followed by healthcare management decisions.

In the first step, the authors have to decompose their research question and set up a hierarchy for the AHP. Therefore, we have seen that most of the authors rely on literature research and expert opinions. This proceeding could carry the risk to not including further important criteria that have not been covered before but that are important for the overall problem and for the complete hierarchy. In particular, the perspective of the participants



25

20

0


number of reported criteria

Fig. 6 Evaluation Results for Reporting Quality 
(in contrast to previous research) could require new criteria for the AHP.

The review showed wide fields for choosing participants in the AHP studies, even though a large portion of papers described their samples as experts or potential consumers of goods or services in question. Sample size was an important factor in these studies, for while there is no precise rule, there is general consensus that the AHP does not require a particularly large sample [23]. Consequently, it should be noted that the results are not necessarily representative. The number of participants ranged from 1 (a single author who judged the AHP for himself) to almost 1,300 with the mean being about 109. This wide range could influence the studies' results. The evaluation of reporting in Subsection 3.2 examined satisfactory reporting of the participants in most of the papers. However, common rules for the process should be developed and several of its aspects improved upon. For instance, future research should develop a standardized method for calculating the sample size. Furthermore, the identification of the correct study sample is imperative in order to answer the studies' research question properly.

In some cases, the participants were invited to revise their answers in case of inconsistency, and thereby, participants could be unsettled and biased. However, inconsistent judging could also be an indicator of overstraining the participants. Furthermore, most of these studies carried out the AHP on an individual basis, whereas only four authors mentioned group decisions. This was an unexpected finding because the AHP was introduced initially to study group decisions. However, our evaluation of the studies' reporting showed that only six authors did not mention whether they had conducted group or individual decisions. Moreover, the aggregation of the AHP results from the individual level to a group did not present a uniform set of results. The advantage of group consensus is that it allows for the discussion of pairwise comparisons, which, in turn, improves participants' understanding of the problem and criteria, and thereby, participants answer less inconsistently. This is because, on the one hand, they discuss their decisions before they set their judgments, but on the other hand, it may be because of the consensus or average extreme judgments being compensated by the group. Thus, the quality of the decision, seen as consistency, is improved [112]. Otherwise, the composition of the group would be a highly influential factor in the process of reaching consensus. This is because individuals within the group could have opposite priorities or else could be unwilling to discuss their positions. In this case, it would not be possible to reach a unanimous vote. Thus, another alternative is to aggregate the individual judgments [113]. In order to do this, one may take the geometric mean or median of either the individual judgments or the individual weights. One prerequisite is that the reciprocal of the aggregated values must correspond to the individual reciprocal values [28]; this can be achieved only by taking the geometric mean [113]. Unfortunately, only 29 of the 69 studies describe their exact processes for calculating the weights, but 39 reported using the EV in some way.

Recently, researchers have paid some attention to whether the results of these studies are robust. Despite the fact that sensitivity analyses could offer more information on the problem of rank reversal as well as the interpretation of the outcome [23], only 14 out of the 69 studies that we examine reported conducting such tests $[73,76,78,82,93,107]$. However, sensitivity analysis for AHP is relevant only when alternatives are included in the hierarchy. Consequently, 25 of 37 studies from our analysis missed reporting sensitivity analyses, as shown in Appendix: Table 2. One study without alternatives in the hierarchy suggested the use of standard deviations for weights [80]. The other sensitivity analysis presented in Subsection 1.1 requires a firm understanding of matrix algebra, does not yield fast or easy solutions, and is not supported by any software package. Although Expert Choice ${ }^{\bullet}$ provides the opportunity for sensitivity analysis, it offers only graphical simulation of one weight at the first hierarchical level [31]. Despite these challenges, sensitivity analyses remain vitally important as they allow researchers to assess the robustness of judgments, identify critical criteria or alternatives, find consensus through a range of judgments, and investigate different scenarios that support the decision [31]. Recently, Broekhuizen et al. have taken a further step concerning sensitivity analysis by providing an overview of dealing with uncertainty in multi-criteria decision making [114]. The results from sensitivity analysis can indicate potential rank reversal. The long-running dispute of rank reversal in AHP raised the question of "[...] the validity of AHP and the legitimacy of rank reversal" [42]. Wang et al. [42] argued that rank reversal is not only a phenomenon in the AHP but also in other decision making approaches. Saaty stated that the relative measurement of alternatives in the AHP implied by definition that all included alternatives were relevant, in contrast to utility theory that could face rank reversal problems [115]. Apart from these fundamental questions, several authors have suggested modifications to the AHP to overcome the problem of rank reversal [116].

Our evaluation of the reported criteria emphasizes the need to increase the number of given information in AHP studies. In general, authors should improve reporting on methodology, which is essential for comprehending and reproducing other authors' results. This would serve to facilitate other researchers' evaluations of study quality. In our opinion, two central explanations are possible for the current underreporting in the literature. First, the AHP, 
being fairly new, has few precisely formulated methodological rules. Second, what rules there are do not hold in practice. The latter observation also encompasses cases in which the AHP was too difficult for participants, either because of the formulations of the criteria or because of the method itself. It can be concluded that further research, in particular, methodological research, is needed in this field.

Although this study is based on systematic literature research and transparent evaluation criteria, there are a number of limitations that bear mentioning. As we primarily conducted our research on the Pubmed and Web of Science databases, it is possible that we did not include all relevant articles from other databases, even though we conducted a manual research. In addition, not all studies reported their procedures and methodologies in detail; therefore, the resulting statements in this review and the evaluation of the studies' reporting could be biased, as we were restricted to available information. We are unable to make statements about the appropriateness of the evaluated content, like the sample size. By contrast, our evaluation criteria considered only whether a point was mentioned. Furthermore, the evaluation of reporting relied on the CONSORT and PRISMA Statements in order to develop criteria for the AHP. These statements suggest evaluation criteria for RCTs and systematic literature reviews, thus it could be criticized that we apply them to the subjective method of the AHP. The importance of each criterion can be criticized and our overall evaluation provides only an indication of the studies' reporting with respect to informational content-not the quality. Moreover, we summarized the articles' procedures but were unable to convey their results without some adaptions and generalizations; some aspects of the AHP must be adapted to suit the situation.

\section{Conclusion}

We found that there is a pressing need to develop methodological standards for the AHP; otherwise, discrepancies in methodology could bias studies' results. In particular, future research should establish a standard procedure for aggregating individual data, specifically, a standard for using the geometric mean versus the arithmetic mean and aggregating judgments or priorities. We should place special emphasis on finding practical sensitivity analysis to address the criticisms regarding rank reversal due to changed judgments. In addition, suggestions are necessary for reporting the robustness of weights for AHPs that do not include alternatives.

Besides the methodological aspects of the AHP, we should also think about the topic that is researched. We carved out that the AHP is based on the hierarchical structure and the criteria that are included. If the author uses improper assumptions, he will find biased results. Therefore, the AHP hierarchy should not only base on one source of information but also on a combination of different methods (e.g. literature research and expert interview). Hence, further research is required about how to determine the interviewees, what should be done with inconsistent answers, and how the outcomes and the stability of the results should be presented. In the future, we need new insights as to which target groups can best handle the challenges of the AHP. These challenges are mainly consistent answering, preventing overstraining by using adequate numbers of pairwise comparisons, and deciding between group and individual AHP. Therefore, researchers should investigate specific groups, like elderly people, healthy people, and patients with different diseases or disabilities.

In our study, we analyzed whether authors reported important aspects of the AHP in their studies. This could be a first step to evaluate the quality of studies applying AHP in healthcare. In addition, guidelines should be formulated as to which statistics should be reported and how to conduct high-quality AHPs. As mentioned before, Bridges et al. published a checklist that contains recommendations for conducting conjoint analyses on healthcare topics on behalf of the International Society for Pharmacoeconomics and Outcomes Research (ISPOR) group [9]. Besides aspects for study presentation, it suggests criteria for evaluating the choice of attributes and the appropriateness of the method for the research question. Still further, we should take the current criticisms of the AHP into consideration so that we can find solutions to address them.

This systematic literature review shows a heterogeneous picture for application of the AHP in health economics research. It is likely that interest in the AHP will rise in the future, particularly in its application to health economic evaluations, the weighing of therapy outcomes, and benefit assessments. In this context, the AHP method could support decision making regarding reimbursement of pharmaceuticals. This is largely owing to its ability to translate complex questions into stepwise comparisons at different hierarchical levels. In these hierarchies, both quantitative and qualitative criteria can be compared, which provides a more accurate representation of real-world healthcare issues. Therefore, it should be used for complex decision problems that can completely be decomposed into a hierarchical structure. Thus, patients could apply the AHP to clarify their priorities. The patients could also benefit from these structured decisions in conversations with their physicians. The second important point is to figure out by researches which are the appropriate participants that are able to judge this research problem reliably. 


\section{Appendix}

Table 1 Key words for systematic literature review

\begin{tabular}{|c|c|c|c|}
\hline & Search terms & Pubmed & Web of Science \\
\hline \multirow[t]{7}{*}{ Block A } & Analytic Hierarchy Process & 481 & 10,127 \\
\hline & Analytical Hierarchy Process & 486 & 3,148 \\
\hline & multi-criteria decision analysis & 236 & 2,821 \\
\hline & multiple criteria decision & 2,135 & 8,291 \\
\hline & stated preference & 977 & 32,773 \\
\hline & Expert Choice & 2,676 & 5,601 \\
\hline & pairwise comparison & 2,873 & 10,385 \\
\hline \multirow[t]{2}{*}{ Block B } & Health economics & 283,801 & 10,684 \\
\hline & Health care & $1,346,972$ & 412,669 \\
\hline \multirow[t]{3}{*}{ Combination Block A } & $\begin{array}{l}\text { Analytic Hierarchy Process OR Analytical Hierarchy Process OR multi-criteria decision analysis } \\
\text { OR multiple criteria decision OR stated preference OR Expert Choice OR pairwise comparison }\end{array}$ & 9,685 & 68,767 \\
\hline & $\begin{array}{l}\text { (Analytic Hierarchy Process[Title/Abstract]) OR (Analytical Hierarchy Process[Title/Abstract]) } \\
\text { OR (multi-criteria decision analysis[Title/Abstract]) OR (multiple criteria decision[Title/Abstract]) } \\
\text { OR (stated preference[Title/Abstract]) OR (Expert Choice[Title/Abstract]) OR (pairwise } \\
\text { comparison[Title/Abstract] ) }\end{array}$ & 1,966 & 4,923 \\
\hline & $\begin{array}{l}\text { (Analytic Hierarchy Process[Title/Abstract]) OR (Analytical Hierarchy Process[Title/Abstract]) } \\
\text { OR (multi-criteria decision analysis[Title/Abstract]) OR (multiple criteria decision[Title/Abstract]) } \\
\text { OR (stated preference[Title/Abstract]) OR (pairwise comparison[Title/Abstract] ) }\end{array}$ & 1,956 & 4,829 \\
\hline \multirow[t]{2}{*}{ Block A AND Block B } & $\begin{array}{l}\text { (Analytic Hierarchy Process OR Analytical Hierarchy Process OR multi-criteria decision analysis } \\
\text { OR multiple criteria decision OR stated preference OR pairwise comparison) AND health care }\end{array}$ & 306 & 137 \\
\hline & $\begin{array}{l}\text { ((Analytic Hierarchy Process[Title/Abstract]) OR (Analytical Hierarchy Process[Title/Abstract]) } \\
\text { OR (multi-criteria decision analysis[Title/Abstract]) OR (multiple criteria decision[Title/Abstract]) } \\
\text { OR (stated preference[Title/Abstract]) OR (Expert Choice[Title/Abstract]) OR (pairwise } \\
\text { comparison[Title/Abstract])) AND health care }\end{array}$ & 307 & 139 \\
\hline Final search & $\begin{array}{l}\text { (Analytic Hierarchy Process[Title/Abstract]) OR (Analytical Hierarchy Process[Title/Abstract]) } \\
\text { OR (multi-criteria decision analysis[Title/Abstract]) OR (multiple criteria decision[Title/Abstract]) } \\
\text { OR (stated preference[Title/Abstract]) OR (pairwise comparison[Title/Abstract]) Filter: } \\
\text { Language English, German }\end{array}$ & 1,839 & 4,474 \\
\hline
\end{tabular}


Table 2 Evaluation of reporting quality

\begin{tabular}{|c|c|c|c|c|c|c|c|c|c|c|c|c|}
\hline Authors & Year & $\begin{array}{l}\text { Decision goal, } \\
\text { criteria (and } \\
\text { alternatives) }\end{array}$ & $\begin{array}{l}\text { Number of } \\
\text { participants }\end{array}$ & $\begin{array}{l}\text { Type of } \\
\text { participants }\end{array}$ & Decision & $\begin{array}{l}\text { Scale for } \\
\text { pairwise } \\
\text { comparisons }\end{array}$ & $\begin{array}{l}\text { Interview } \\
\text { process }\end{array}$ & Software & $C R$ & $\begin{array}{l}\text { Calculation } \\
\text { of weights }\end{array}$ & $\begin{array}{l}\text { Sensitivity } \\
\text { analysis }\end{array}$ & $\begin{array}{l}\text { Reported } \\
\text { elements }\end{array}$ \\
\hline Ajami S, Ketabi S [92] & 2012 & yes & 3 hospitals & $E$ & $g$ & $9-1-9$ & $f 2 f$ & Expert Choice ${ }^{\circledast}$ & $n / a$ & $\mathrm{EV}, \mathrm{GA}$ & $\mathrm{n} / \mathrm{a}$ (alt) & 8 \\
\hline Bahadori M et al. [117] & 2014 & yes & 48 & $\mathrm{E}$ & $g$ & $9-1-9$ & $\begin{array}{l}\text { nominal } \\
\text { group } \\
\text { technique }\end{array}$ & Expert Choice ${ }^{\circledast}$ & 1 & $\mathrm{n} / \mathrm{a}$ & $\mathrm{n} / \mathrm{a}(\mathrm{alt})$ & 8 \\
\hline Basoglu N et al. [69] & 2012 & yes & 14 & $\mathrm{P}$ & ind & $\mathrm{n} / \mathrm{a}$ & $\mathrm{n} / \mathrm{a}$ & $\mathrm{n} / \mathrm{a}$ & $\mathrm{n} / \mathrm{a}$ & $\mathrm{n} / \mathrm{a}$ & $\mathrm{n} / \mathrm{a}(\mathrm{alt})$ & 4 \\
\hline Bi Y, Lai D, Yan H [45] & 2010 & yes & $\mathrm{n} / \mathrm{a}$ & $\mathrm{E}$ & $\mathrm{n} / \mathrm{a}$ & $1-9$ & $f 2 f$ & SPSS & 0.1 & EV & $\mathrm{n} / \mathrm{a}$ & 6 \\
\hline Cabrera-Barona P et al. [50] & 2015 & yes & 32 & $\mathrm{E}$ & $\mathrm{n} / \mathrm{a}$ & $9-1-9$ & $\mathrm{n} / \mathrm{a}$ & $\mathrm{n} / \mathrm{a}$ & 0.1 & $\mathrm{n} / \mathrm{a}$ & $\mathrm{n} / \mathrm{a}$ & 5 \\
\hline $\begin{array}{l}\text { Cancela J, Fico G, } \\
\text { Arredondo Waldmeyer MT } \\
\text { [51] }\end{array}$ & 2015 & yes & 16 & $E$ & ind $+g$ & $1-9$ & online & BPMSG & 0.1 & $\mathrm{n} / \mathrm{a}$, median & $\mathrm{n} / \mathrm{a}$ & 9 \\
\hline Chen L et al. [70] & 2014 & yes & 102 & C & ind & $1-5$ & online & $\mathrm{n} / \mathrm{a}$ & 0.2 & $\mathrm{n} / \mathrm{a}$ & $\mathrm{n} / \mathrm{a}(\mathrm{alt})$ & 7 \\
\hline Chung KP et al. [71] & 2013 & yes & 66 & $E$ & ind & $9-1-9$ & email & n/a & 0.1 & EV & $\mathrm{n} / \mathrm{a}(\mathrm{alt})$ & 8 \\
\hline Danner M et al. [72] & 2011 & yes & 19 (12P, 7E) & $E+P$ & g & $9-1-9$ & $\begin{array}{l}\text { f2f } \\
\text { (workshop) }\end{array}$ & Expert Choice ${ }^{\circledast}$ & $<0.1$ & EV, GGM & $\mathrm{n} / \mathrm{a}$ & 9 \\
\hline Diaz-Ledezma C et al. [107] & 2014 & yes & 1 & A & $\mathrm{n} / \mathrm{a}$ & $9-1-9$ & $\mathrm{n} / \mathrm{a}$ & SuperDecisionsTM & 0.1 & $\mathrm{n} / \mathrm{a}$ & yes (alt) & 7 \\
\hline $\begin{array}{l}\text { Diaz-Ledezma C, Parvizi J } \\
\text { [73] }\end{array}$ & 2013 & yes & 1 & A & $n / a$ & $9-1-9$ & lit & SuperDecisionsTM & 0.1 & $\mathrm{n} / \mathrm{a}$ & yes (alt) & 8 \\
\hline Dolan JG et al. [25] & 2013 & yes & 484 & $P$ & ind & $9-1-9$ & $f 2 f$ & $\begin{array}{l}\text { Excel, Crystal } \\
\text { Xcelsius, Expert } \\
\text { Choice }^{\oplus}\end{array}$ & 0.15 & EV & $\mathrm{n} / \mathrm{a}(\mathrm{alt})$ & 9 \\
\hline Dou L et al. [61] & 2015 & yes & 40 & $E$ & ind & $1 / 9-1-9$ & $\begin{array}{l}\text { delphi } \\
\text { method }\end{array}$ & Expert Choice & 0.1 & $\mathrm{n} / \mathrm{a}$ & $\mathrm{n} / \mathrm{a}$ & 8 \\
\hline Fang LF, Tung HH [104] & 2010 & yes & 65 & $\mathrm{E}$ & ind & $\mathrm{n} / \mathrm{a}$ & questionnaire & SPSS & $\mathrm{n} / \mathrm{a}$ & $\mathrm{EV}, \mathrm{GA}$ & $\mathrm{n} / \mathrm{a}$ & 7 \\
\hline $\begin{array}{l}\text { Guariguata L, Whiting D } \\
\text { [110] }\end{array}$ & 2011 & yes & 10 & E & ind & $5-1-5$ & questionnaire & $\mathrm{n} / \mathrm{a}$ & $\mathrm{n} / \mathrm{a}$ & $\mathrm{n} / \mathrm{a}, \mathrm{GA}$ & $\mathrm{n} / \mathrm{a}$ (alt) & 7 \\
\hline Hilgerink MP et al. [93] & 2011 & yes & 7 & $\mathrm{E}$ & ind $+g$ & $\mathrm{n} / \mathrm{a}$ & $\begin{array}{l}\text { f2f } \\
\text { (discussion) }\end{array}$ & Expert Choice ${ }^{\circledast}$ & $\mathrm{n} / \mathrm{a}$ & $\mathrm{EV}, \mathrm{GGM}$ & yes (alt) & 8 \\
\hline Hou D et al. [67] & 2014 & yes & $\mathrm{n} / \mathrm{a}$ & $E$ & $n / a$ & $\mathrm{n} / \mathrm{a}$ & lit & n/a & 0.1 & $\mathrm{n} / \mathrm{a}$ & $\mathrm{n} / \mathrm{a}$ & 4 \\
\hline Hsu HC et al. [90] & 2010 & yes & $\mathrm{n} / \mathrm{a}$ & $\mathrm{E}$ & ind & $5-1-5$ & $f 2 f$ & MS Excel & $\mathrm{n} / \mathrm{a}$ & $\mathrm{EV}, \mathrm{GGM}$ & $\mathrm{n} / \mathrm{a}$ (alt) & 7 \\
\hline $\begin{array}{l}\text { Hsu JC, Tang DH, Lu CY } \\
\text { [63] }\end{array}$ & 2015 & yes & $\mathrm{n} / \mathrm{a}$ & $\mathrm{n} / \mathrm{a}$ & $\mathrm{n} / \mathrm{a}$ & $\mathrm{n} / \mathrm{a}$ & $\mathrm{n} / \mathrm{a}$ & $\mathrm{n} / \mathrm{a}$ & $\mathrm{n} / \mathrm{a}$ & $\mathrm{n} / \mathrm{a}$ & $\mathrm{n} / \mathrm{a}$ & 1 \\
\hline $\begin{array}{l}\text { Hsu JC, Hsieh, C-Y, Yang Y- } \\
\text { HK, Lu CY [65] }\end{array}$ & 2015 & yes & $\mathrm{n} / \mathrm{a}$ & $\mathrm{n} / \mathrm{a}$ & $\mathrm{n} / \mathrm{a}$ & $\mathrm{n} / \mathrm{a}$ & $\mathrm{n} / \mathrm{a}$ & n/a & $\mathrm{n} / \mathrm{a}$ & EV & $\mathrm{n} / \mathrm{a}$ (alt) & 2 \\
\hline Hu H et al. [68] & 2010 & yes & $\mathrm{n} / \mathrm{a}$ & $E$ & $\mathrm{n} / \mathrm{a}$ & $\mathrm{n} / \mathrm{a}$ & $\mathrm{n} / \mathrm{a}$ & n/a & $\mathrm{n} / \mathrm{a}$ & $\mathrm{n} / \mathrm{a}, \mathrm{GGM}$ & $\mathrm{n} / \mathrm{a}$ & 3 \\
\hline Hummel JM et al. [94] & 2012 & yes & 6 & $\mathrm{E}$ & ind & $9-1-9$ & questionnaire & $\mathrm{n} / \mathrm{a}$ & $\mathrm{n} / \mathrm{a}$ & $\mathrm{EV}, \mathrm{GGM}$ & $\mathrm{n} / \mathrm{a}$ (alt) & 7 \\
\hline ljzerman MJ et al. [95] & 2012 & yes & 86 & $E+P$ & ind $+g$ & $9-1-9$ & $\mathrm{ppq}$ & Expert Choice ${ }^{\circledast}$ & $\mathrm{n} / \mathrm{a}$ & EV & $\mathrm{n} / \mathrm{a}(\mathrm{alt})$ & 8 \\
\hline
\end{tabular}


Table 2 Evaluation of reporting quality (Continued)

\begin{tabular}{|c|c|c|c|c|c|c|c|c|c|c|c|c|}
\hline Jaberidoost $\mathrm{M}$ et al. [66] & 2015 & yes & $n / a$ & $\bar{E}$ & ind & $1-9$ & questionnaire & Expert Choice ${ }^{\circledast}$ & $\mathrm{n} / \mathrm{a}$ & EV, GGM & $\mathrm{n} / \mathrm{a}$ & 7 \\
\hline Joshi V et al. [74] & 2011 & yes & 58 & E & ind & $1-11$ & online & $\mathrm{n} / \mathrm{a}$ & 0.1 & $\mathrm{n} / \mathrm{a}$ & $\mathrm{n} / \mathrm{a}$ & 7 \\
\hline Joshi $\vee$ et al. [20] & 2014 & yes & 422 & E & ind & $1-4$ & online & own software & 0.1 & $\mathrm{n} / \mathrm{a}$ & $\mathrm{n} / \mathrm{a}$ & 8 \\
\hline Kadohira M [64] & 2015 & yes & 313 & $E+C$ & ind & $\mathrm{n} / \mathrm{a}$ & $\begin{array}{l}\text { workshop, } \\
\text { email }\end{array}$ & ASHtools.xls & 0.15 & $\mathrm{n} / \mathrm{a}, \mathrm{GA}$ & $\mathrm{n} / \mathrm{a}$ (alt) & 8 \\
\hline Karagiannidis A et al. [46] & 2010 & yes & $\mathrm{n} / \mathrm{a}$ & E & g & $1-9$ & $\mathrm{n} / \mathrm{a}$ & Expert Choice ${ }^{\circledast}$ & 0.1 & EV & yes (alt) & 8 \\
\hline Kitamura Y [47] & 2010 & yes & 31 & $P$ & ind & $1-7$ & online & $\mathrm{n} / \mathrm{a}$ & 0.3 & EV & $\mathrm{n} / \mathrm{a}(\mathrm{alt})$ & 7 \\
\hline $\begin{array}{l}\text { Krishnamoorthy K, } \\
\text { Mahalingam M [100] }\end{array}$ & 2015 & yes & $\mathrm{n} / \mathrm{a}$ & $\mathrm{n} / \mathrm{a}$ & $\mathrm{n} / \mathrm{a}$ & $1 / 9-1-9$ & $\mathrm{n} / \mathrm{a}$ & Expert Choice ${ }^{\circledast}$ & 0.1 & EV & yes (alt) & 6 \\
\hline $\begin{array}{l}\text { Kunasekaran V, } \\
\text { Krishnamoorthy K [101] }\end{array}$ & 2014 & yes & $\mathrm{n} / \mathrm{a}$ & $\mathrm{n} / \mathrm{a}$ & $\mathrm{n} / \mathrm{a}$ & $1 / 9-1-9$ & $\mathrm{n} / \mathrm{a}$ & Expert Choice ${ }^{\oplus}$ & 0.1 & $\mathrm{n} / \mathrm{a}$ & yes (alt) & 5 \\
\hline Kuruoglu E et al. [98] & 2015 & yes & 96 & $\mathrm{P}$ & ind & $1-9$ & $f 2 f$ & Expert Choice ${ }^{\oplus}$ & 0.1 & $\begin{array}{l}\mathrm{n} / \mathrm{a} \text {, median } \\
\text { of } \\
\text { judgments }\end{array}$ & $\mathrm{n} / \mathrm{a}$ & 9 \\
\hline $\begin{array}{l}\text { Lambooij MS, Hummel MJ } \\
\text { [75] }\end{array}$ & 2013 & yes & 66 & $E+P$ & ind & $9-1-9$ & online & $\mathrm{n} / \mathrm{a}$ & $\begin{array}{l}0.15 \text { (in } \\
\text { group) }\end{array}$ & $\mathrm{EV}, \mathrm{GA}$ & $\mathrm{n} / \mathrm{a}$ (alt) & 8 \\
\hline Lee CW, Kwak NK [76] & 2011 & yes & $\mathrm{n} / \mathrm{a}$ & E & $\mathrm{n} / \mathrm{a}$ & $\mathrm{n} / \mathrm{a}$ & $\mathrm{n} / \mathrm{a}$ & $\mathrm{n} / \mathrm{a}$ & 0.1 & EV & yes (alt) & 5 \\
\hline Lee WC et al. [52] & 2015 & yes & 200 & C & $\mathrm{n} / \mathrm{a}$ & $1-9$ & $\mathrm{n} / \mathrm{a}$ & Matlab & $\mathrm{n} / \mathrm{a}$ & $\mathrm{n} / \mathrm{a}$ & $\mathrm{n} / \mathrm{a}(\mathrm{alt})$ & 5 \\
\hline Li A-T, Lin J-W [77] & 2014 & yes & 25 & E & ind & $1-9$ & email & Excel & 0.1 & $\mathrm{n} / \mathrm{a}$ & $\mathrm{n} / \mathrm{a}$ & 8 \\
\hline Li C, Yu C [78] & 2013 & yes & $\mathrm{n} / \mathrm{a}$ & E & $\mathrm{n} / \mathrm{a}$ & $\mathrm{n} / \mathrm{a}$ & $\mathrm{n} / \mathrm{a}$ & $\mathrm{n} / \mathrm{a}$ & $\mathrm{n} / \mathrm{a}$ & $\mathrm{n} / \mathrm{a}$ & yes (alt) & 3 \\
\hline Lin RH, Chuang CL [91] & 2010 & yes & 5 & E & $\mathrm{n} / \mathrm{a}$ & $1-9$ & questionnaire & Expert Choice ${ }^{\circledast}$ & 0.1 & $\mathrm{EV}, \mathrm{GGM}$ & $\mathrm{n} / \mathrm{a}$ & 8 \\
\hline Lu L et al. [53] & 2015 & yes & $\mathrm{n} / \mathrm{a}$ & $\mathrm{n} / \mathrm{a}$ & $\mathrm{n} / \mathrm{a}$ & $\mathrm{n} / \mathrm{a}$ & $\mathrm{n} / \mathrm{a}$ & SPSS & $n / a$ & $\mathrm{n} / \mathrm{a}$ & yes & 3 \\
\hline Maruthur NM et al. [111] & 2015 & yes & 9 & E & ind & $\begin{array}{l}\text { "usual AHP } \\
\text { scale" }\end{array}$ & computer & Expert Choice ${ }^{\circledast}$ & 0.15 & $\mathrm{EV}, \mathrm{GGM}$ & yes (alt) & 10 \\
\hline Mok H-P et al. [85] & 2014 & yes & $\mathrm{n} / \mathrm{a}$ & E & $\mathrm{n} / \mathrm{a}$ & $\mathrm{n} / \mathrm{a}$ & $\mathrm{n} / \mathrm{a}$ & $\mathrm{n} / \mathrm{a}$ & 0.01 & $\mathrm{n} / \mathrm{a}$ & $\mathrm{n} / \mathrm{a}$ & 3 \\
\hline $\begin{array}{l}\text { Moslehi S, Atefi Manesh P, } \\
\text { Sarabi Asiabar A [54] }\end{array}$ & 2015 & yes & 5 & E & $\mathrm{n} / \mathrm{a}$ & $1-9$ & $\mathrm{n} / \mathrm{a}$ & $\begin{array}{l}\text { K-Goepel Version } \\
\text { 9.5.2012 }\end{array}$ & 0.072 & $\mathrm{n} / \mathrm{a}$ & $\mathrm{n} / \mathrm{a}$ & 6 \\
\hline Mühlbacher AC et al. [55] & 2015 & yes & 1283 & P & ind & $9-1-9$ & online & $\mathrm{n} / \mathrm{a}$ & $\begin{array}{l}0.006 \\
0.005\end{array}$ & EV & $\mathrm{n} / \mathrm{a}$ & 8 \\
\hline $\begin{array}{l}\text { Mühlbacher AC, Juhnke C, } \\
\text { Kaczynski A [60] }\end{array}$ & 2015 & yes & 24 & $P$ & ind $+g$ & $9-1-(-9)$ & $\begin{array}{l}\text { group } \\
\text { discussion }\end{array}$ & $\mathrm{n} / \mathrm{a}$ & 0.1 & $\begin{array}{l}\text { EV, } \\
\text { consensus }\end{array}$ & $\mathrm{n} / \mathrm{a}$ & 8 \\
\hline $\begin{array}{l}\text { Munoz DA, Nembhard HB, } \\
\text { Kraschnewski Jennifer L } \\
\text { [109] }\end{array}$ & 2014 & yes & 1 & A & ind & $1-9$ & $\mathrm{n} / \mathrm{a}$ & $\mathrm{n} / \mathrm{a}$ & 0.1 & EV & $\mathrm{n} / \mathrm{a}$ & 7 \\
\hline Olivieri A et al. [79] & 2012 & yes & 7 & E & ind & $1 / 9-1-9$ & questionnaire & $\mathrm{n} / \mathrm{a}$ & $\mathrm{n} / \mathrm{a}$ & $\mathrm{n} / \mathrm{a}, \mathrm{GGM}$ & $\mathrm{n} / \mathrm{a}(\mathrm{alt})$ & 7 \\
\hline Page K [80] & 2012 & yes & 94 & C & ind & $9-1-9$ & $\mathrm{ppq}$ & SPSS & $\begin{array}{l}\text { average at } \\
0.3\end{array}$ & EV & SD & 10 \\
\hline Papadopoulos A et al. [56] & 2015 & yes & 7 & E & ind & $1-9$ & $\mathrm{n} / \mathrm{a}$ & $\mathrm{n} / \mathrm{a}$ & 0.1 & $\mathrm{EV}, \mathrm{GGM}$ & yes (alt) & 8 \\
\hline
\end{tabular}


Table 2 Evaluation of reporting quality (Continued)

\begin{tabular}{|c|c|c|c|c|c|c|c|c|c|c|c|c|}
\hline Pecchia L et al. [81] & 2011 & yes & 63 & $E$ & ind & $5-1-5$ & online & $\mathrm{n} / \mathrm{a}$ & 0.2 & $\mathrm{EV}, \mathrm{WM}$ & $n / a$ & 8 \\
\hline Pecchia L et al. [26] & 2013 & yes & 5 & E & ind & $5-1-5$ & $\mathrm{ppq}$ & $\mathrm{n} / \mathrm{a}$ & 0.1 & EV & $\mathrm{n} / \mathrm{a}$ & 8 \\
\hline Perseghin P et al. [96] & 2014 & yes & 11 & E & g & $1-9$ & email & $\mathrm{n} / \mathrm{a}$ & $\mathrm{n} / \mathrm{a}$ & $\mathrm{n} / \mathrm{a}, \mathrm{GA}$ & $\mathrm{n} / \mathrm{a}$ & 7 \\
\hline Petit J et al. [108] & 2012 & yes & $\mathrm{n} / \mathrm{a}$ & A & $\mathrm{n} / \mathrm{a}$ & $9-1-9$ & $\mathrm{n} / \mathrm{a}$ & $\mathrm{n} / \mathrm{a}$ & 0.1 & EV & $\mathrm{n} / \mathrm{a}(\mathrm{alt})$ & 5 \\
\hline Ramezanpour B et al. [57] & 2015 & yes & 24 & E & g & $1-9$ & $\mathrm{n} / \mathrm{a}$ & $\mathrm{n} / \mathrm{a}$ & 0.1 & EV & $\mathrm{n} / \mathrm{a}$ & 7 \\
\hline Reddy BP et al. [86] & 2014 & yes & 8 & E & ind $+g$ & $1 / 9-1-9$ & $\begin{array}{l}\text { workshop, } \\
\text { email }\end{array}$ & $\mathrm{n} / \mathrm{a}$ & "standard" & $\begin{array}{l}\text { EV, GGM } \\
\text { and } \\
\text { consensus }\end{array}$ & yes (alt) & 9 \\
\hline Riepe MW [99] & 2015 & yes & 42 & E & ind & $6-1-6$ & workshop & $\begin{array}{l}\text { SPSS, spreadsheet } \\
\text { file }\end{array}$ & 0.1 & $\mathrm{n} / \mathrm{a}$ & $\mathrm{n} / \mathrm{a}$ & 8 \\
\hline Sharma PS et al. [82] & 2011 & yes & 96 & $P$ & ind & $9-1-9$ & $\begin{array}{l}\text { f2f, } \\
\text { (computer) }\end{array}$ & $\mathrm{n} / \mathrm{a}$ & $\mathrm{n} / \mathrm{a}$ & $\mathrm{n} / \mathrm{a}$ & $\begin{array}{l}\text { one-way } \\
\text { for hybrid } \\
\text { (alt) }\end{array}$ & 7 \\
\hline Shojaei P et al. [87] & 2014 & yes & 30 & E & ind & $9-1-1 / 9$ & $f 2 f$ & Expert Choice ${ }^{\circledast}$ & 0.1 & $\mathrm{EV}, \mathrm{GGM}$ & $\mathrm{n} / \mathrm{a}(\mathrm{alt})$ & 9 \\
\hline $\begin{array}{l}\text { Smith J, Cook A, Packer C } \\
\text { [48] }\end{array}$ & 2010 & yes & $\begin{array}{l}4 \text { experienced } \\
\text { horizon } \\
\text { analysts }\end{array}$ & E & $\mathrm{n} / \mathrm{a}$ & $\mathrm{n} / \mathrm{a}$ & $\mathrm{n} / \mathrm{a}$ & $\mathrm{n} / \mathrm{a}$ & $\mathrm{n} / \mathrm{a}$ & $\mathrm{n} / \mathrm{a}$ & $\mathrm{n} / \mathrm{a}(\mathrm{alt})$ & 3 \\
\hline Šoltés V, Gavurová B [88] & 2014 & yes & 16 & E & ind & $1-9$ & $\mathrm{n} / \mathrm{a}$ & MS Excel & 0.1 (for $\mathrm{Cl}$ ) & EV & $\mathrm{n} / \mathrm{a}$ (alt) & 8 \\
\hline Suner A et al. [83] & 2012 & yes & 5 & E & ind & $9-1-9$ & online & Expert Choice ${ }^{\circledast}$ & 0.1 & EV & $\mathrm{n} / \mathrm{a}$ & 9 \\
\hline Taghipour H et al. [49] & 2014 & yes & 40 hospitals & E & g & $\mathrm{n} / \mathrm{a}$ & $\mathrm{n} / \mathrm{a}$ & $\begin{array}{l}\text { Expert Choice }{ }^{\oplus} \\
\text { MS Excel }\end{array}$ & 0.1 & $\mathrm{EV}, \mathrm{WM}$ & $\mathrm{n} / \mathrm{a}(\mathrm{alt})$ & 7 \\
\hline Tu C et al. [89] & 2014 & yes & 41 & E & ind & $1-9$ & $\mathrm{n} / \mathrm{a}$ & $\mathrm{n} / \mathrm{a}$ & 0.1 & $E V, G A$ & $\mathrm{n} / \mathrm{a}(\mathrm{alt})$ & 7 \\
\hline Uzoka FM et al. [97] & 2011 & yes & 6 & E & ind & $9-1-9$ & $\mathrm{n} / \mathrm{a}$ & $\mathrm{n} / \mathrm{a}$ & 0.2 & $\mathrm{EV}, \mathrm{GA}$ & $\mathrm{n} / \mathrm{a}$ & 7 \\
\hline Velmurugan R et al. [102] & 2011 & yes & $\mathrm{n} / \mathrm{a}$ & $\mathrm{n} / \mathrm{a}$ & $\mathrm{n} / \mathrm{a}$ & $9-1-9$ & $\mathrm{n} / \mathrm{a}$ & $n / a$ & 0.1 & AN & $\mathrm{n} / \mathrm{a}(\mathrm{alt})$ & 4 \\
\hline Wollmann D et al. [103] & 2012 & yes & 400 & C & ind & $9-1-9$ & $\mathrm{n} / \mathrm{a}$ & $\mathrm{n} / \mathrm{a}$ & $\begin{array}{l}\text { procedure } \\
\text { by Silvac }\end{array}$ & $\mathrm{n} / \mathrm{a}, \mathrm{GGM}$ & $\mathrm{n} / \mathrm{a}(\mathrm{alt})$ & 7 \\
\hline Xu X, Cao Y, Luan X [58] & 2014 & yes & $\mathrm{n} / \mathrm{a}$ & E & $\mathrm{n} / \mathrm{a}$ & $1-9$ & $\begin{array}{l}\text { mobile } \\
\text { phone app }\end{array}$ & $\mathrm{n} / \mathrm{a}$ & $\mathrm{n} / \mathrm{a}$ & $\mathrm{n} / \mathrm{a}$ & $\mathrm{n} / \mathrm{a}$ & 4 \\
\hline Xu Y et al. [59] & 2015 & yes & 954 & $P$ & ind & $1-4$ & email & SAS & 0.15 & $\begin{array}{l}\mathrm{EV}, \\
\text { arithmetic } \\
\text { mean }\end{array}$ & $\mathrm{n} / \mathrm{a}(\mathrm{alt})$ & 9 \\
\hline Zhang S et al. [106] & 2015 & yes & $\mathrm{n} / \mathrm{a}$ & E & $\mathrm{n} / \mathrm{a}$ & $1-5$ & $\mathrm{n} / \mathrm{a}$ & JMP10.0 & $\mathrm{n} / \mathrm{a}$ & $\mathrm{n} / \mathrm{a}$ & $\mathrm{n} / \mathrm{a}$ & 4 \\
\hline Zhu Q et al. [62] & 2014 & yes & 9 & E & ind & $1-9$ & $n / a$ & $\mathrm{n} / \mathrm{a}$ & 0.1 & $\mathrm{EV}, \mathrm{GA}$ & $\mathrm{n} / \mathrm{a}$ & 7 \\
\hline
\end{tabular}

$P$ patients, C potential consumers, E Experts, $n / a$ not applicable, ind individual, $g$ group, online online or web-based questionnaire, f2f face-to-face interview, lit literature, quest questionnaire (not further defined), $p p q$ paper-pencil questionnaire, email mailed questionnaire, $C R$ accepted consistency ratio, EV Eigenvector method, GA group average, GGM group geometric mean, WM weighted means, $A N$ additive normalization method, alt alternatives included in the study, SD standard deviation 
Table $\mathbf{3}$ List of all included studies

\begin{tabular}{|c|c|c|c|c|c|c|}
\hline Author & Year & Title & Journal & Volume & Issue & Page \\
\hline Ajami S, Ketabi S & 2012 & $\begin{array}{l}\text { Performance evaluation of medical records } \\
\text { departments by analytical hierarchy process } \\
\text { (AHP) approach in the selected hospitals } \\
\text { in Isfahan }\end{array}$ & Journal of Medical Systems & 36 & 3 & $1165-1171$ \\
\hline Angelucci E et al. & 2008 & $\begin{array}{l}\text { Italian Society of Hematology practice } \\
\text { guidelines for the management of iron } \\
\text { overload in thalassemia major and related } \\
\text { disorders }\end{array}$ & Hematology journal & 93 & 5 & $741-752$ \\
\hline Bahadori $\mathrm{M}$ et al. & 2014 & $\begin{array}{l}\text { Assessing the service quality of Iran military } \\
\text { hospitals: Joint Commission International } \\
\text { standards and Analytic Hierarchy Process } \\
\text { (AHP) technique }\end{array}$ & $\begin{array}{l}\text { Journal of education and } \\
\text { health promotion }\end{array}$ & 3 & & 98 \\
\hline Balestra G et al. & 2007 & $\begin{array}{l}\text { AHP for the acquisition of biomedical } \\
\text { instrumentation }\end{array}$ & $\begin{array}{l}\text { Engineering in Medicine and } \\
\text { Biology Society-Conference } \\
\text { proceedings: 29th Annual } \\
\text { International Conference } \\
\text { of the IEEE }\end{array}$ & & & $3581-3584$ \\
\hline Barosi G et al. & 2007 & $\begin{array}{l}\text { A unified definition of clinical resistance- } \\
\text { intolerance to hydroxyurea in essential } \\
\text { thrombocythemia: results of a consensus } \\
\text { process by an intl. working group }\end{array}$ & Leukemia & 21 & 2 & $277-280$ \\
\hline Basoglu N, Daim TU, Topacan U & 2012 & $\begin{array}{l}\text { Determining patient preferences for remote } \\
\text { monitoring }\end{array}$ & Journal of Medical Systems & 36 & 3 & $1389-1401$ \\
\hline Baykasoğlu A, Dereli T, Yılankırkan N & 2009 & $\begin{array}{l}\text { Application of cost-benefit analysis for } \\
\text { surgical gown and drape selection: a } \\
\text { case study }\end{array}$ & $\begin{array}{l}\text { American Journal of Infection } \\
\text { Control }\end{array}$ & 37 & 3 & $215-226$ \\
\hline Bi Y, Lai D, Yan H & 2010 & $\begin{array}{l}\text { Synthetic evaluation of the effect of health } \\
\text { promotion: impact of a UNICEF project in } \\
40 \text { poor western counties of China }\end{array}$ & Public Health & 124 & 7 & $376-391$ \\
\hline Brent A C et al. & 2007 & $\begin{array}{l}\text { Application of the analytical hierarchy } \\
\text { process to establish health care waste } \\
\text { management systems that minimise } \\
\text { infection risks in developing countries }\end{array}$ & $\begin{array}{l}\text { European Journal of Operational } \\
\text { Research }\end{array}$ & 181 & & $403-424$ \\
\hline Cabrera-Barona P et al. & 2015 & $\begin{array}{l}\text { A multi-criteria spatial deprivation index } \\
\text { to support health inequality analyses }\end{array}$ & $\begin{array}{l}\text { International journal of health } \\
\text { geographics }\end{array}$ & 14 & & 11 \\
\hline Cancela J et al. & 2015 & $\begin{array}{l}\text { Using the Analytic Hierarchy Process (AHP) } \\
\text { to understand the most important factors } \\
\text { to design and evaluate a telehealth system } \\
\text { for Parkinson's disease }\end{array}$ & $\begin{array}{l}\text { BMC medical informatics and } \\
\text { decision making }\end{array}$ & 15 & Suppl & S7 \\
\hline Carter KJ et al. & 1999 & $\begin{array}{l}\text { Analysis of three decision-making methods: } \\
\text { a breast cancer patient as a model }\end{array}$ & Medical Decision Making & 19 & 1 & $49-57$ \\
\hline Castro F et al. & 1996 & Sequential test selection in the analysis of & Medical Decision Making & 16 & 2 & $178-183$ \\
\hline
\end{tabular}


Table 3 List of all included studies (Continued)

Chang PY et al

Cheever MA et al.

Chen $L$ et al.

Cho KT, Kim SM

Chung KP et al.

Cook DR, Staschak S, Green WT

Czaja S et al.

da Rocha LS, Sloane EB, Bassani JWM

Danner $\mathrm{M}$ et al.

Dey P K, Hariharan S, Clegg B

Diaz-Ledezma C et al.

Diaz-Ledezma C et al

Diaz-Ledezma C, Parvizi J

Dolan JG
2006 Factors influencing medical students choice of specialty

2009 The prioritization of cancer antigens: a national cancer institute pilot project for the acceleration of translational research

2014 Development of a decision support engine to assist patients with hospital selection

2003 Selecting medical devices and materials for development in Korea: the analytic hierarchy process approach

2013 Application of the analytic hierarchy process in the performance measurement of colorectal cancer care for the design of a pay-for-performance program in Taiwan

1990 Equitable allocation of livers for orthotopic transplantation: an application of the Analytic Hierarchy Process

2003 A methodology for describing and decomposing complex psychosocial and behavioral interventions

2005 Optimal Medical Equipment Maintenance Service Proposal Decision Support System combining Activity Based Costing (ABC) and the Analytic Hierarchy Process (AHP)

2011 Integrating patients' views into health technology assessment: AHP as a method to elict patient preferences

2006 Measuring the operational performance of intensive care units using the analytic hierarchy process approach

2014 Diagnosis of Periprosthetic Joint Infection in Medicare Patients: Multicriteria Decision Analysis

2014 Diagnosis of Periprosthetic Joint Infection in Medicare Patients: Multicriteria Decision Analysis

2013 Surgical approaches for cam femoroacetabular impingement: the use of multicriteria decision analysis

2000 Involving patients in decisions regarding preventive health interventions using the analytic hierarchy process
Journal of the Formosan Medical Association $105 \quad 6 \quad$ 489-496

= Taiwan yi zhi

Clinical Cancer Research

$15 \quad 17 \quad 5323-5337$

Journal of medical systems

$38 \quad 6 \quad 59$

International Journal of Health

Planning and Management

$18 \quad 2$

$161-174$

International Journal for Quality

in Health Care

European Journal of Operational Research

9-56

Psychology and Aging

$18 \quad 3 \quad 385-395$

Conference proceedings: 27th Annual International Conference of the IEEE Engineering in Medicine and Biology Society

International Journal of Technology

Assessment in Health Care

International Journal of Operations\& Production Management

Clinical Orthopaedics and Related Research

Clinical Orthopaedics and Related Research

Clinical Orthopaedics and Related Research

Health Expectations 
Table 3 List of all included studies (Continued)

Dolan JG

Dolan JG

Dolan JG

Dolan JG et al.

Dolan JG, Bordley DR

Dolan JG, Bordley DR

Dolan JG, Bordley DR, Miller H

Dolan JG, Frisina S

Dolan JG, ladarola S

Dolan JG, Isselhardt BJ, Cappuccio JD

Dou L et al.

Eden KB et al.

Fang LF, Tung $\mathrm{HH}$

Guariguata L, Whiting D

Hannan EL, O’Donnell J, Freedland T
1995 Are patients capable of using the analytic hierarchy process and willing to use it to help make clinical decisions

1990 Can decision analysis adequately represent clinical problems?

1989 Medical decision making using the analytic hierarchy process: choice of initial antimicrobia therapy for acute pyelonephritis

2013 Patients' Preferences and Priorities Regarding Colorectal Cancer Screening

1994 Isoniazid prophylaxis-The Importance of Individual Values

1993 Involving patients in complex decisions about their care: an approach using the analytic hierarchy process

1993 Diagnostic strategies in the management of acute upper gastrointestinal bleeding: patient and physician preferences

2002 Randomized controlled trial of a patient decision aid for colorectal cancer screening

2008 Risk communication formats for low probability events - an exploratory study of patient preferences

1989 The analyic hierarchy process in medical decision making: a tutorial

2015 An evaluation system for financial compensation in traditional Chinese medicine services

2009 Patients were more consistent in randomized trial at prioritizing childbirth preferences using graphic-numeric than verbal formats

2010 Comparison of nurse practitioner job core competency expectations of nurse managers, nurse practitioners, and physicians in Taiwan

2011 The International Diabetes Federation diabetes atlas methodology for estimating global and national prevalence of diabetes in adults

1981 A priority assignment model for standard and conditions in a long term care survey
Medical Decision Making

15

$76-80$

Journal of Clinical Epidemiology

$43 \quad 3$

$277-284$

Medical Decision Making

$51-56$

Medical Decision Making

$33 \quad 1 \quad 59-70$

Medical Decision Making

$14 \quad 1 \quad 1-8$

Journal of General Internal Medicine

$4 \quad 204-209$

Journal of General Internal Medicine

$10 \quad 525-529$

Medical Decision Making

$22 \quad 2 \quad 125-139$

BMC medical informatics and

decision making [electronic resource]

URL: http://www.ncbi.

nlm.nih.gov/pmc/articles/ PMC2330036/ Accessed 31 De 2013.

Medical Decision Making

Complementary therapies in

40-50

medicine

Journal of Clinical Epidemiology

$23 \quad 5$

$637-643$

624

$415-424$

ournal of the American Academy

of Nurse Practitioners

Diabetes Research and Clinical Practice

$322-332$

Socio-economic Planning Sciences

$15-6-277-289$ 
Table 3 List of all included studies (Continued)

Hariharan S et al.

Hariharan S et al.

Hilgerink MP et al.

Hou D et al.

Hsu HC et al.

$\mathrm{Hu} \mathrm{H}$ et al.

Hummel JM et al.

Hummel JM et al.

Hummel JM et al.

Hsu JC et al.

Hsu JC, Tang DH, Lu CY

ljzerman MJ, van Til JA, Bridges JFP

ljzerman MJ, van Til JA, Snoek GJ

Jaberidoost $\mathrm{M}$ et al.
2005 Application of analytic hierarchy process for measuring and comparing the global performance of intensive care units

2004 A new tool for measurement of processbased performance of multispecialty tertiary care hospitals

2011 Assessment of the added value of the Twente Photoacoustic Mammoscope in breast cancer diagnosis

2014 A real-time, dynamic early-warning mode based on uncertainty analysis and risk assessment for sudden water pollution accidents

2010 Constructing area-level indicators of successful ageing in Taiwan

2010 Establishment and evaluation of a model of a community health service in an underdeveloped area of China

2012 Predicting the Health Economic Performance of new non-fusion Surgery in Adolescent Idiopathic Scoliosis

2005 A multicriteria decision analysis of augmentative treatment of upper limbs in persons with tetraplegia

2000 Medical technology assessment: the use of the analytic hierarchy process as a too for multidisciplinary evaluation of medica devices

2015 Net clinical benefit of oral anticoagulants: a multiple criteria decision analysis

2015 Risk-benefit assessment of oral phosphodiesterase type 5 inhibitors for treatment of erectile dysfunction: a multiple criteria decision analysis

2012 A Comparison of Analytic Hierarchy Process and Conjoint Analysis Methods in assessing treatment alternatives for stroke Rehabilitation

2008 Comparison of two multi-criteria decision techniques for eliciting treatment preferences in people with neurological disorders

2015 Pharmaceutical supply chain risk assessment in Iran using analytic hierarchy process (AHP) and simple additive weighting (SAW) methods
Journal of Critical Care

20

$117-125$

International Journal of Health

Care Quality Assurance

Medical Devices: Evidence

and Research

Environmental science and pollution

research internationa

Health and Social Care in the

Community

Public Health

Orthopaedic Research Society

Journal of Rehabilitation

Research \& Development

International Journal of Artificia

Organs

PLoS One

International journal of clinical practice



4

The Patient

The Patient

Journal of pharmaceutical policy and practice 
Table 3 List of all included studies (Continued)

Javalgi RG, Rao SR, Thomas EG

Joshi $V$ et al.

Joshi $\vee$ et al.

Kadohira $\mathrm{M}$ et al.

Karagiannidis A et al.

Karamouz $\mathrm{M}$ et al.

Katsumura $Y$ et al.

Kitamura $Y$

Koch T, Ridgley M

Koch T, Rowell M

Krishnamoorthy K, Mahalingam M

Kunasekaran V, Krishnamoorthy K

Kuruoglu E, Guldal D, Mevsim V, Gunvar T

Kwak NK, McCarthy K, Parker GE

Lambooij MS, Hummel M
1991 Choosing a hospital: analysis of consumer tradeoffs

2011 Empirical investigation of radiologists' priorities for PACS selection: an analytical hierarchy process approach

2014 PACS Administrators' and Radiologists' Perspective on the Importance of Features for PACS Selection

2015 Stakeholder prioritization of zoonoses in Japan with analytic hierarchy process method

2010 A multi-criteria assessment of scenarios on thermal processing of infectious hospital wastes: a case study for Central Macedonia

2007 Developing a master plan for hospital solid waste management: a case study

2008 Relationship between risk information on total colonoscopy and patient preferences for colorectal cancer screening options: Analysis using the Analytic Hierarchy Process

2010 Decision-making process of patients with gynecological cancer regarding their cancer treatment choices using the analytic hierarchy process

1998 Distanced Perspectives: AIDS, Anencephaly, and AHP

1999 The dream of consensus: finding common ground in a bioethical context

2015 Selection of a suitable method for the preparation of polymeric nanoparticles: multi-criteria decision making approach

2014 Multi criteria decision making to select the best method for the preparation of solid lipid nanoparticles of rasagiline mesylate using analytic hierarchy process

2015 Kuruoglu, Emel; Guldal, Dilek; Mevsim, Vildan; Gunvar, Tolga

1997 A human resource planning model for hospital/medical technologists: an analytic hierarchy process approach

2013 Differentiating innovation priorities among stakeholder in hospital care
Journal of Health Care Marketing

Journal of Digital Imaging

Journal of digital imaging

pidemiology and infection

Waste Management

Waste Management

BMC Health Services Research

Japan Journal of Nursing Science

Theoretical Medicine and Bioethics

Theoretical Medicine and Bioethics

Advanced pharmaceutical bulletin

Journal of advanced pharmaceutica technology \& research

BMC medical informatics and decision making

Journal of Medical Systems

BMC Medical Informatics and

Decision Making
$19 \quad 1 \quad 47-58$

$20 \quad 3 \quad 261-273$

5

$115-121$

63

$21 \quad 3 \quad 173-187$

URL: http://www.biomed central.com/1472-6947/13/91 Accessed 31 Dec 2013. 
Table 3 List of all included studies (Continued)

Lee CW, Kwak NK

Lee WC et al.

Li A-T, Lin J-W

Li C, Yu C

Lin RH, Chuang CL

Lu L et al.

Maruthur NM et al.

Matsuda S

Matsuda S, Washino K

Mok H-P et al.

Moslehi S, Atefi Manesh P, Sarabi Asiabar A

Mühlbacher AC et al.

Mühlbacher AC, Juhnke C, Kaczynski A

Munoz DA, Nembhard HB, Kraschnewski JL

Nuijten MJC, Kosa J
2011 Strategic Enterprise Resource Planning in a Health-Care System Using a Multicriteria Decision-Making Model

2015 A speedy cardiovascular diseases classifier using multiple criteria decision analysis

2014 Constructing core competency indicators for clinical teachers in Taiwan: a qualitative analysis and an analytic hierarchy process

2013 Performance Evaluation of Public Non-Profit Hospitals Using a BP Artificial Neural NetworkThe Case of Hubei Province in China

2010 A hybrid diagnosis model for determining the types of the liver disease

2015 Assessment of regional human health risks from lead contamination in Yunnan province, southwestern China

2015 Use of the analytic hierarchy process for medication decision-making in type 2 diabetes

1996 An analysis of the Vietnamese system of occupational safety and health and setting priorities with the analytical hierarchy process

1998 How do the Japanese medical students evaluate the effectiveness of anti-smoking strategies- an application of the Analytic Hierarchy Process

2014 Development and validation of a convenient formula evaluating the value and applicability of medical literature in clinical practice

2015 Quality measurement indicators for Iranian Health Centers

2015 Objective Criteria in the Medicinal Therapy for Type II Diabetes: An Analysis of the Patients' Perspective with Analytic Hierarchy Process and Best-Worst Scaling

2015 Patients' Priorities in the Treatment of Neuroendocrine Tumours: An Analytica Hierarchy Process

2014 Quantifying complexity in translational research: an integrated approach

2004 Pricing of pharmaceuticals: Assessing the pricing potential by a pricing matrix model
Journal of Medical Systems

$265-275$

Sensors

BMC medical education

$1312-1320$

International Journal of Environmenta Research and Public Health

Computers in Biology and Medicine

PLoS One

103

e0119562

PLoS One

Occupational and Environmental Medicine

Environmental Health and Preventive Medicine

Pakistan journal of medical sciences

Medical journal of the Islamic

Republic of Iran

online

Gesundheitswesen

Gesundheitswesen

online

International journal of health

care quality

assurance

The European Journal of Health Economics 
Table 3 List of all included studies (Continued)

Oddershede Herrera A, Carrasco González R, Barham Abu-Muhor E

Olivieri A et al

Page K

Papadopoulos A et al.

Pecchia L et al

Pecchia L et al.

Perseghin P et al.

Petit J et al.

Ramezanpour B et al

Reddy BP et al.

Richman MB et a.l

Riepe MW

Ross ME, Nydick RL

Sharma PS et al.

Shin T et al.
2008 Multi-criteria Decision Model for Assessing Health Service Information Technology Network Support Using the Analytic Hierarchy Process

2012 Proposed definition of 'poor mobilizer' in lymphoma and multiple myeloma: an analytic hierarchy process by ad hoc working group Gruppo ItalianoTrapianto di Midollo

2012 The four principles: can they be measured and do they predict ethical decision making

2015 TDS exposure project: application of the analytic hierarchy process for the prioritization of substances to be analyzed in a total diet study

2011 Analytic Hierarchy Process (AHP) for examining healthcare professionals' assessments of risk factors

2013 User needs elicitation via analytic hierarchy process (AHP). A case study on a Computed Tomography (CT) scanner

2014 A policy for the disposal of autologous hematopoietic progenitor cells: report from an Italian consens

2012 Softening the Rule of Five- where to draw the line?

2015 Market implementation of the MVA platform for pre-pandemic and pandemic influenza vaccines: A quantitative key opinion leader analysis

2014 Prioritising public health guidance topics in the National Institute for Health and Care Excellence using the Analytic Hierarchy Process

2005 A novel computer based expert decision making model for prostate cancer disease management

2015 Clinical preference for factors in treatmen of geriatric depression

1992 Selection of licensing candidates in the pharmaceutical industry: an application of the analytic hierarchy process

2011 Subjective risk vs. objective risk can lead to different post-cesarean birth decisions based on multiattribute modeling

2009 The comparative evaluation of expanded national immunization policies in Korea using an analytic hierarchy process
Computatión y sistemas

$173-182$

Bone Marrow Transplantation

$47 \quad 3$

$342-351$

BMC Medical Ethics

10 online

Food and chemical toxicology : an

international journal published for

the British Industrial Biological

Research Association

Methods of Information in Medicine

$35-444$

BMC medical informatics and

decision making [electronic resource]

Transfusion

Bioorganic \& Medicinal Chemistry

5343-5351

Vaccine

Neuropsychiatric disease and

$$
\text { 25-31 }
$$

treatment

Journal of Health Care Marketing

12

Journal of Clinical Epidemiology

Vaccine

$27 \quad 5$


Table 3 List of all included studies (Continued)

Shojaei $\mathrm{P}$ et al.

Singh S, Dolan JG, Centor RM

Smith J, Cook A, Packer C

Šoltés V, Gavurová B

Suner $\mathrm{A}$ et al.

Taghipour $\mathrm{H}$ et al.

Tan $\mathrm{X}$ et al.

Tarimcilar MM, Khaksari SZ

Tu C et al.

Tzung TY et al.

Uzoka FM et al.

van Til JA et al.

Velmurugan R, Selvamuthukumar S, Manavalan R

Wang $\mathrm{Kl}$ et al.

Weingarten MS et al.
2014 Ranking the effects of urban development projects on social determinants of health: health impact assessment

2006 Optimal management of adults with pharyngitis-a multi-criteria decision analysis

2010 Evaluation criteria to assess the value of identification sources for horizon scanning

2014 The functionality comparison of the health care systems by the analytical hierarchy process method

2012 Sequential decision tree using the analytic hierarchy process for decision support in rectal cancer

2014 On-site or off-site treatment of medical waste: a challenge

2007 Evaluation of the Effect of a Health Education Campaign of HIV by Using an Analytical Hierarchy Process Method

1991 Capital budgeting in hospital management using the analytic hierarchy process

2014 Application of the analytic hierarchy process to a risk assessment of emerging infectious diseases in Shaoxing city in southern China

2007 Decision factors and the recognition of medical specialty in patients receiving cosmetic laser and intense pulsed light treatment

2011 An experimental comparison of fuzzy logic and analytic hierarchy process for medical decision support systems

2008 The use of the analytic hierarchy process to aid decision making in acquired equinovarus deformity

2011 Multi criteria decision making to select the suitable method for the preparation of nanoparticles using an analytical hierarchy process

2007 Analysis of senior medical students' preferences in specialty choice a survey in a medical school in northern Taiwan

1997 A pilot study of the use of analytic hierarchy process for the Selection of Surgery Residents

Global journal of health science

BMC Medical Informatics and

Decision Making

International Journal of Technology

Assessment in Health Care

E + M Ekonomie a Management

Artificial Intelligence in Medicine

Journal of environmental health

science \& engineering

International journal of Environmental Research and Public Health

Socio-economic Planning Sciences

Japanese journal of infectious diseases

Dermatologic Surgery

Computer Methods and Programs in Biomedicine

Archives of Physical Medicine and Rehabilitation

Die Pharmazie

Chang Gung Medical Journal

Academic medicine: journal of the Association of American Medical Colleges

\section{$100-117$}

$59-68$

68

$254-259$

27-34

$417-422$

1488-1493

$10-27$

$457-462$

836-842

339-353

400-402 
Table 3 List of all included studies (Continued)

\section{Wollmann $\mathrm{D}$ et al.}

Wu C, Lin C, Chen $\mathrm{H}$.

Xu X, Cao Y, Luan X

Xu Y et al.

Zhang $S$ et al.

Zhu Q et al.
2012 Evaluation of health service providers by consumers through the Analytic Hierarchy Process Method

2007 Optimal selection of location for Taiwanese hospitals to ensure a competitive advantage
by using the analytic hierarchy process and sensitivity analysis

2014 Application of 4G wireless network-based system for remote diagnosis and nursing of stomal complications

2015 Comparison of patient preferences for fecal immunochemical test or colonoscopy using the analytic hierarchy process

2015 Indicators for Environment Health Risk Assessment in the Jiangsu Province of China

2014 The spatial distribution of health vulnerability to heat waves in Guangdong Province, China
Revista de Saúde Pública

Building and Environment

46

$777-783$

$1431-1444$

International journal of clinical and experimental medicine

BMC health services research

$4554-4561$

International journal of

environmental research

and public health

Global Health Action 


\section{Abbreviations}

AHP: Analytic Hierarchy Process; CHERH: Center for Health Economics Research Hannover; CONSORT: Consolidated Standards of Reporting Trials; CR: Consistency Ratio; EV: Eigenvector method; IQWiG: Institute for Quality and Efficiency in Health Care; ISPOR: International Society for Pharmacoeconomics and Outcomes Research; PRISMA: Preferred Reporting Items for Systematic Reviews and Meta-Analyses.

\section{Competing interests}

The author(s) declare that they have no competing interests.

\section{Authors' contributions}

KS carried out the analyses and drafted the manuscript. IA and IH participated in the review process and decision making process for identifying relevant articles. IA made substantial contributions to conception of the article. $\mathrm{IH}$ collected and prepared the data adequately for the manuscript. KD participated in selection process of papers and she revised the manuscript. JMS revised the manuscript for important intellectual content. All authors read and approved the final manuscript.

\section{Acknowledgements}

The Center for Health Economics Research Hannover (CHERH) is founded by the Federal Ministry of Education and Research.

\section{Author details}

${ }^{1}$ Center for Health Economics Research Hannover (CHERH), Leibniz University of Hanover, Otto-Brenner-Str. 1, 30159 Hannover, Germany. ${ }^{2}$ Institute for Risk and Insurance, Leibniz University of Hanover, Otto-Brenner-Str. 1, 30159 Hannover, Germany.

\section{Received: 14 August 2015 Accepted: 15 December 2015} Published online: 24 December 2015

\section{References}

1. Gesetz zur Neuordnung des Arzneimittelmarktes in der gesetzlichen Krankenversicherung (Arzneimittelneuordnungsgesetz -AMNOG).

2. Hailey D, Nordwall M. Survey on the involvement of consumers in health technology assessment programs. Int J Technol Assess Health Care. 2006; 22(4):497-9.

3. Buttorff $\mathrm{C}$. What should be the role of patient preferences in making health care resource allocation decisions?; Available from: http://www.ispor.org/ News/articles/August10/What-Should-Be-the-Role-of-Patient-Preferences.asp.

4. Bruera E, Sweeney C, Calder K, Palmer L, Benisch-Tolley S. Patient preferences versus physician perceptions of treatment decisions in cancer care. J Clin Oncol. 2001;19:2883-5.

5. Mühlbacher AC, Juhnke C. Patient preferences versus physicians' judgement: does it make a difference in healthcare decision making? Appl Health Econ Health Policy. 2013;11:163-80.

6. Gaston CM, Mitchell G. Information giving and decision-making in patients with advanced cancer: a systematic review. Soc Sci Med. 2005;61:2252-64.

7. Dolan JG. Multi-criteria clinical decision support: A primer on the use of multiple criteria decision making methods to promote evidence-based, patient-centered healthcare. Patient. 2010;3:229-48.

8. Institute for Quality and Efficiency in Health Care. Allgemeine Methoden: Entwurf für Version 4.2 vom 18.06.2014. [November 27, 2014]; Available from: https://www.iqwig.de/download/IQWiG_Methoden_Entwurf-fuerVersion-4-2.pdf.

9. Bridges JFP, Hauber AB, Marshall D, Lloyd A, Prosser LA, Regier DA, et al. Conjoint analysis applications in health-a checklist: a report of the ISPOR Good Research Practices for Conjoint Analysis Task Force. Value Health. 2011;14:403-13.

10. Marshall D, Bridges JFP, Hauber B, Cameron R, Donnalley L, Fyie K, et al. Conjoint Analysis Applications in Health - How are Studies being Designed and Reported?: An Update on Current Practice in the Published Literature between 2005 and 2008. The patient. 2010;3:249-56.

11. Ryan M. Using conjoint analysis to elicit preferences for health care. BMJ. 2000;320:1530-3.

12. Saaty TL. A scaling method for priorities in hierarchical structures. J Math Psychol. 1977;15:234-81.

13. Saaty TL. The analytic hierarchy process: planning, priority setting, resource allocation 1980 .
14. Dolan JG. Medical decision making using the analytic hierarchy process: choice of initial antimicrobial therapy for acute pyelonephritis. Med Decis Making. 1989;9:51-6.

15. Dolan JG, Isselhardt Jr BJ, Cappuccio JD. The analytic hierarchy process in medical decision making: a tutorial. Med Decis Making. 1989;9:40-50.

16. Liberatore MJ, Nydick RL. The analytic hierarchy process in medical and health care decision making: A literature review. Eur J Oper Res. 2008;189: 194-207.

17. Cook DR, Staschak S, Green WT. Equitable allocation of livers for orthotopic transplantation: an application of the Analytic Hierarchy Process. Eur J Oper Res. 1990;48:49-56.

18. Dolan JG, Bordley DR, Miller H. Diagnostic strategies in the management of acute upper gastrointestinal bleeding: patient and physician preferences. J Gen Intern Med. 1993;8:525-9.

19. Cheever MA, Allison JP, Ferris AS, Finn OJ, Hastings BM, Hecht TT, et al. The prioritization of cancer antigens: a national cancer institute pilot project for the acceleration of translational research. Clin Cancer Res. 2009;15:5323-37.

20. Joshi V, Narra VR, Joshi K, Lee K, Melson D. PACS Administrators' and Radiologists' Perspective on the Importance of Features for PACS Selection. J Digit Imaging. 2014;27:486-95.

21. de Bekker-Grob EW, Ryan M, Gerard K. Discrete choice experiments in health economics: a review of the literature. Health Econ. 2012;21:145-72.

22. Hummel M, IJzerman M (eds.). The past and future of the AHP in health care decision making; 2011.

23. Mühlbacher A, Kaczynski A. Der Analytic Hierarchy Process (AHP): Eine Methode zur Entscheidungsunterstützung im Gesundheitswesen. PharmacoEcon Ger Res Artic. 2013;11:119-32.

24. Saaty RW. The analytic hierarchy process - what it is and how it is used. Mathematical Modelling. 1987;9:161-76.

25. Dolan JG, Boohaker E, Allison J, Imperiale TF. Patients' preferences and priorities regarding colorectal cancer screening. Med Decis Making. 2013;33: 59-70.

26. Pecchia L, Martin JL, Ragozzino A, Vanzanella C, Scognamiglio A, Mirarchi L, et al. User needs elicitation via analytic hierarchy process (AHP). A case study on a Computed Tomography (CT) scanner. BMC Med Inform Decis Mak. 2013;13:2

27. Srdjevic B. Combining different prioritization methods in the analytic hierarchy process synthesis. Comput Oper Res. 2005;32:1897-919.

28. Saaty TL. Decision making with the analytic hierarchy process. International journal of services sciences. 2008;1:83-98.

29. Meixner O, Haas R. Wissensmanagement und Entscheidungstheorie: Mit 35 Tabellen. Wien: Facultas.wuv; 2010.

30. Forman E, Peniwati K. Aggregating individual judgments and priorities with the analytic hierarchy process. Eur J Oper Res. 1998;108:165-9.

31. Chen $H$, Kocaoglu DF. A sensitivity analysis algorithm for hierarchical decision models. Eur J Oper Res. 2008;185:266-88.

32. Saaty TL, Vargas LG. Sensitivity analysis in the analytic hierarchy process. In: Saaty TL, Vargas LG, editors. Decision making with the analytic network process. Boston: Springer US; 2013. p. 345-60

33. Arbel A. Approximate articulation of preference and priority derivation. Eur Oper Res. 1989:43:317-26.

34. Moreno-Jimenez JM, Vargas LG. A probabilistic study of preference structures in the analytic hierarchy process with interval judgments. Math Comput Model. 1993;17:73-81.

35. Sugihara $\mathrm{K}$, Tanaka $\mathrm{H}$. Interval evaluations in the analytic hierarchy process by possibility analysis. Computational Intell. 2001;17:567-79.

36. Triantaphyllou E, Sánchez A. A sensitivity analysis approach for some deterministic multi-criteria decision-making methods. Decis Sci. 1997;28: 151-94.

37. Sowlati T, Assadi P, Paradi JC. Developing a mathematical programming model for sensitivity analysis in analytic hierarchy process. IJMOR. 2010;2:290.

38. Masuda T. Hierarchical sensitivity analysis of priority used in analytic hierarchy process. Int J of Systems Sc. 1990;21:415-27.

39. Huang Y. Enhancement on sensitivity analysis of priority in analytic hierarchy process. Int J Gen Syst. 2010;31:531-42.

40. Erkut $\mathrm{E}$, Tarimcilar M. On sensitivity analysis in the analytic hierarchy process. IMA J Management Math. 1991;3:61-83.

41. Altuzarra A Moreno-Jiménez JM Salvador M Consensus building in AHPgroup decision making: A Bayesian approach. Oper Res. 2010;58:1755-73.

42. Wang Y, Luo Y. On rank reversal in decision analysis. Math Comput Model. 2009:49:1221-9. 
43. Moher D, Schulz KF, Altman DG. The CONSORT statement. Revised recommendations for improving the quality of reports of parallel group randomized trails. BMC Med Res Methodol. 2001;1:2.

44. Moher D. Preferred reporting items for systematic reviews and metaanalyses: The PRISMA statement. Ann Intern Med. 2009;151:264.

45. Bi Y, Lai D, Yan $H$. Synthetic evaluation of the effect of health promotion: impact of a UNICEF project in 40 poor western counties of China. Public Health. 2010;124:376-91.

46. Karagiannidis A, Papageorgiou A, Perkoulidis G, Sanida G, Samaras P. A multicriteria assessment of scenarios on thermal processing of infectious hospital wastes: a case study for Central Macedonia. Waste Manag. 2010;30:251-62.

47. Kitamura Y. Decision-making process of patients with gynecological cancer regarding their cancer treatment choices using the analytic hierarchy process. Jpn J Nurs Sci. 2010;7:148-57.

48. Smith J, Cook A, Packer C. Evaluation criteria to assess the value of identification sources for horizon scanning. Int J Technol Assess Health Care. 2010;26:348-53.

49. Taghipour H, Mohammadyarei T, Asghari Jafarabadi M, Asl HA. On-site or off-site treatment of medical waste: a challenge. J Environ Health Sci Eng. 2014;12:68.

50. Cabrera-Barona P, Murphy T, Kienberger S, Blaschke T. A multi-criteria spatial deprivation index to support health inequality analyses. Int J Health Geogr. 2015;14:11.

51. Cancela J, Fico G, Arredondo Waldmeyer MT. Using the Analytic Hierarchy Process (AHP) to understand the most important factors to design and evaluate a telehealth system for Parkinson's disease. BMC Med Inform Decis Mak. 2015;15 Suppl 3:S7.

52. Lee WC, Hung FH, Tsang KF, Tung HC, Lau WH, Rakocevic V, et al. A speedy cardiovascular diseases classifier using multiple criteria decision analysis. Sensors (Basel). 2015;15:1312-20.

53. Lu L, Cheng H, Liu X, Xie J, Li Q, Zhou T. Assessment of regional human health risks from lead contamination in Yunnan province, southwestern China. PLoS One. 2015;10:e0119562.

54. Moslehi S, Atefi Manesh P, Sarabi AA. Quality measurement indicators for Iranian Health Centers. Med J Islam Repub Iran. 2015;29:177.

55. Mühlbacher AC, Bethge S, Kaczynski A, Juhnke C. Objective Criteria in the Medicinal Therapy for Type II Diabetes: An Analysis of the Patients' Perspective with Analytic Hierarchy Process and Best-Worst Scaling. Gesundheitswesen. 2015. https://www.thieme-connect.com/DOI/DOI?10. 1055/s-0034-1390474.

56. Papadopoulos A, Sioen I, Cubadda F, Ozer H, Basegmez HIO, Turrini A, et al. TDS exposure project: application of the analytic hierarchy process for the prioritization of substances to be analyzed in a total diet study. Food Chem Toxicol. 2015;76:46-53

57. Ramezanpour B, Pronker ES, Kreijtz JHCM, Osterhaus ADME, Claassen E. Market implementation of the MVA platform for pre-pandemic and pandemic influenza vaccines: A quantitative key opinion leader analysis. Vaccine. 2015;33:4349-58.

58. Xu X, Cao Y, Luan X. Application of $4 \mathrm{G}$ wireless network-based system for remote diagnosis and nursing of stomal complications. Int J Clin Exp Med. 2014;7:4554-61.

59. Xu Y, Levy BT, Daly JM, Bergus GR, Dunkelberg JC. Comparison of patient preferences for fecal immunochemical test or colonoscopy using the analytic hierarchy process. BMC Health Serv Res. 2015;15:175.

60. Mühlbacher AC, Juhnke C, Kaczynski A. Patients' Priorities in the Treatment of Neuroendocrine Tumours: An Analytical Hierarchy Process. Gesundheitswesen. 2015. https://www.thieme-connect.com/DOI/DOI?10. 1055/s-0035-1548932.

61. Dou L, Yin A, Hao M, Lu J. An evaluation system for financial compensation in traditional Chinese medicine services. Complement Ther Med. 2015;23:637-43.

62. Zhu Q, Liu T, Lin H, Xiao J, Luo Y, Zeng W, et al. The spatial distribution of health vulnerability to heat waves in Guangdong Province. China Glob Health Action. 2014;7:25051.

63. Hsu JC, Tang DH, Lu CY. Risk-benefit assessment of oral phosphodiesterase type 5 inhibitors for treatment of erectile dysfunction: a multiple criteria decision analysis. Int J Clin Pract. 2015:69:436-43.

64. Kadohira M, Hill G, Yoshizaki R, Ota S, Yoshikawa Y. Stakeholder prioritization of zoonoses in Japan with analytic hierarchy process method. Epidemiol Infect. 2015;143:1477-85.

65. Hsu JC, Hsieh C, Yang YK, Lu CY. Net clinical benefit of oral anticoagulants: a multiple criteria decision analysis. PLoS One. 2015;10:e0124806.
66. Jaberidoost M, Olfat L, Hosseini A, Kebriaeezadeh A, Abdollahi M, Alaeddini $M$, et al. Pharmaceutical supply chain risk assessment in Iran using analytic hierarchy process (AHP) and simple additive weighting (SAW) methods. J Pharm Policy Pract. 2015;8:9.

67. Hou D, Ge X, Huang P, Zhang G, Loaiciga H. A real-time, dynamic earlywarning model based on uncertainty analysis and risk assessment for sudden water pollution accidents. Environ Sci Pollut Res Int. 2014;21:8878-92.

68. Hu H, Liang W, Liu M, Li L, Li Z, Li T, et al. Establishment and evaluation of a model of a community health service in an underdeveloped area of China. Public Health. 2010;124:206-17.

69. Basoglu N, Daim TU, Topacan U. Determining patient preferences for remote monitoring. J Med Syst. 2012;36:1389-401.

70. Chen L, Chan C, Lee H, Chung Y, Lai F. Development of a decision support engine to assist patients with hospital selection. J Med Syst. 2014;38:59.

71. Chung K, Chen L, Chang Y, Chang Y, Lai M. Application of the analytic hierarchy process in the performance measurement of colorectal cancer care for the design of a pay-for-performance program in Taiwan. Int I Qual Health Care. 2013;25:81-91.

72. Danner M, Hummel JM, Volz F, van Manen JG, Wiegard B, Dintsios C, et al Integrating patients' views into health technology assessment: Analytic hierarchy process (AHP) as a method to elicit patient preferences. Int J Technol Assess Health Care. 2011;27:369-75.

73. Diaz-Ledezma C, Parvizi J. Surgical approaches for cam femoroacetabular impingement: the use of multicriteria decision analysis. Clin Orthop Relat Res. 2013;471:2509-16.

74. Joshi V, Lee K, Melson D, Narra VR. Empirical investigation of radiologists' priorities for PACS selection: an analytical hierarchy process approach. J Digit Imaging. 2011;24:700-8.

75. Lambooij MS, Hummel MJ. Differentiating innovation priorities among stakeholder in hospital care. BMC Med Inform Decis Mak. 2013:13:91.

76. Lee CW, Kwak NK. Strategic enterprise resource planning in a health-care system using a multicriteria decision-making model. J Med Syst. 2011;35: 265-75

77. Li A, Lin J. Constructing core competency indicators for clinical teachers in Taiwan: a qualitative analysis and an analytic hierarchy process. BMC Med Educ. 2014:14:75.

78. Li C, Yu C. Performance evaluation of public non-profit hospitals using a BP artificial neural network: the case of Hubei Province in China. Int J Environ Res Public Health. 2013;10:3619-33.

79. Olivieri A, Marchetti M, Lemoli R, Tarella C, lacone A, Lanza F, et al. Proposed definition of 'poor mobilizer' in lymphoma and multiple myeloma: an analytic hierarchy process by ad hoc working group Gruppo ItalianoTrapianto di Midollo Osseo. Bone Marrow Transplant. 2012;47:342-51.

80. Page K. The four principles: can they be measured and do they predict ethical decision making? BMC Med Ethics. 2012;13:10.

81. Pecchia L, Bath PA, Pendleton N, Bracale M. Analytic Hierarchy Process (AHP) for examining healthcare professionals' assessments of risk factors. The relative importance of risk factors for falls in community-dwelling older people. Methods Inf Med. 2011:50:435-44.

82. Sharma PS, Eden KB, Guise J, Jimison HB, Dolan JG. Subjective risk vs. objective risk can lead to different post-cesarean birth decisions based on multiattribute modeling. J Clin Epidemiol. 2011;64:67-78.

83. Suner A, Celikoglu CC, Dicle O, Sokmen S. Sequential decision tree using the analytic hierarchy process for decision support in rectal cancer. Artif Intell Med. 2012:56:59-68.

84. Bahadori M, Ravangard R, Yaghoubi M, Alimohammadzadeh K. Assessing the service quality of Iran military hospitals: Joint Commission International standards and Analytic Hierarchy Process (AHP) technique. J Educ Health Promot. 2014;3:98

85. Mok H, Zhou Y, Chen J, Gao Q. Development and validation of a convenient formula evaluating the value and applicability of medical literature in clinical practice. Pak J Med Sci. 2014;30:1377-82.

86. Reddy BP, Kelly MP, Thokala P, Walters SJ, Duenas A. Prioritising public health guidance topics in the National Institute for Health and Care Excellence using the Analytic Hierarchy Process. Public Health. 2014;128: 896-903.

87. Shojaei P, Karimlou M, Nouri J, Mohammadi F, Malek Afzali H, Forouzan AS. Ranking the effects of urban development projects on social determinants of health: health impact assessment. Glob J Health Sci. 2014;6:183-95.

88. Šoltés V, Gavurová B. The functionality comparison of the health care systems by the analytical hierarchy process method. E + M 2014;17:100-17. 
89. Tu C, Fang Y, Huang Z, Tan R. Application of the analytic hierarchy process to a risk assessment of emerging infectious diseases in Shaoxing city in southern China. Jpn J Infect Dis. 2014;67:417-22.

90. Hsu H, Tsai C, Chang M, Luh D. Constructing area-level indicators of successful ageing in Taiwan. Health Soc Care Community. 2010;18:70-81.

91. Lin R, Chuang C. A hybrid diagnosis model for determining the types of the liver disease. Comput Biol Med. 2010;40:665-70.

92. Ajami S, Ketabi S. Performance evaluation of medical records departments by analytical hierarchy process (AHP) approach in the selected hospitals in Isfahan: Medical records dep. \& AHP. J Med Syst. 2012;36:1165-71.

93. Hilgerink MP, Hummel MJ, Manohar S, Vaartjes SR, ljzerman MJ. Assessment of the added value of the Twente Photoacoustic Mammoscope in breast cancer diagnosis. Med Devices (Auckl). 2011;4:107-15.

94. Hummel JM, Boomkamp ISM, Steuten LMG, Verkerke BGJ, ljzerman MJ. Predicting the health economic performance of new non-fusion surgery in adolescent idiopathic scoliosis. J Orthop Res. 2012;30:1453-8.

95. ljzerman MJ, van Til JA, Bridges JFP. A comparison of analytic hierarchy process and conjoint analysis methods in assessing treatment alternatives for stroke rehabilitation. Patient. 2012;5:45-56.

96. Perseghin $\mathrm{P}$, Marchetti M, Pierelli L, Olivieri A, Introna M, Lombardini L, et al. A policy for the disposal of autologous hematopoietic progenitor cells: report from an Italian consensus panel. Transfusion. 2014;54:2353-60.

97. Uzoka FE, Obot O, Barker K, Osuji J. An experimental comparison of fuzzy logic and analytic hierarchy process for medical decision support systems. Comput Methods Programs Biomed. 2011;103:10-27.

98. Kuruoglu E, Guldal D, Mevsim V, Gunvar T. Which family physician should I choose? The analytic hierarchy process approach for ranking of criteria in the selection of a family physician. BMC Med Inform Decis Mak. 2015;15:63.

99. Riepe MW. Clinical preference for factors in treatment of geriatric depression. Neuropsychiatr Dis Treat. 2015;11:25-31.

100. Krishnamoorthy K, Mahalingam M. Selection of a suitable method for the preparation of polymeric nanoparticles: multi-criteria decision making approach. Adv Pharm Bull. 2015;5:57-67.

101. Kunasekaran V, Krishnamoorthy K. Multi criteria decision making to select the best method for the preparation of solid lipid nanoparticles of rasagiline mesylate using analytic hierarchy process. J Adv Pharm Technol Res. 2014;5: 115-21.

102. Velmurugan R, Selvamuthukumar S, Manavalan R. Multi criteria decision making to select the suitable method for the preparation of nanoparticles using an analytical hierarchy process. Pharmazie. 2011;66:836-42.

103. Wollmann D, Steiner MT, Vieira GE, Steiner PA. Evaluation of health service providers by consumers through the Analytic Hierarchy Process Method. Rev Saude Publica. 2012;46:777-83.

104. Fang L, Tung $\mathrm{H}$. Comparison of nurse practitioner job core competency expectations of nurse managers, nurse practitioners, and physicians in Taiwan. J Am Acad Nurse Pract. 2010;22:409-16.

105. Maruthur NM, Joy S, Dolan J, Segal JB, Shihab HM, Singh S. Systematic assessment of benefits and risks: study protocol for a multi-criteria decision analysis using the Analytic Hierarchy Process for comparative effectiveness research. F1000Res. 2013;2:160.

106. Zhang S, Wei Z, Liu W, Yao L, Suo W, Xing J, et al. Indicators for Environment Health Risk Assessment in the Jiangsu Province of China. Int J Environ Res Public Health. 2015;12:11012-24

107. Diaz-Ledezma C, Lichstein PM, Dolan JG, Parvizi J. Diagnosis of periprosthetic joint infection in medicare patients: Multicriteria decision analysis. Clin Orthop Relat Res. 2014;472(11):3275-84.

108. Petit J, Meurice N, Kaiser C, Maggiora G. Softening the rule of five. Where to draw the line? Bioorg Med Chem. 2012;20:5343-51.

109. Munoz DA, Nembhard HB, Kraschnewski JL. Quantifying complexity in translational research: an integrated approach. Int J Health Care Qual Assur. 2014:27:760-76

110. Guariguata L, Whiting D, Weil C, Unwin N. The International Diabetes Federation diabetes atlas methodology for estimating global and national prevalence of diabetes in adults. Diabetes Res Clin Pract. 2011;94:322-32.

111. Maruthur NM, Joy SM, Dolan JG, Shihab HM, Singh S. Use of the analytic hierarchy process for medication decision-making in type 2 diabetes. PLoS One. 2015;10:e0126625.

112. Dyer RF, Forman EH. Group decision support with the Analytic Hierarchy Process. Decis Support Syst. 1992;8:99-124.

113. Saaty TL, Shang JS. Group decision-making: Head-count versus intensity of preference. Socio Econ Plan Sci. 2007:41:22-37.
114. Broekhuizen H, Groothuis-Oudshoorn CGM, van Til JA, Hummel JM, ljzerman MJ. A review and classification of approaches for dealing with uncertainty in multi-criteria decision analysis for healthcare decisions. Pharmacoeconomics. 2015;33:445-55.

115. Saaty TL. How to make a decision: The analytic hierarchy process. Eur J Oper Res. 1990;48:9-26.

116. Maleki H, Zahir S. A comprehensive literature review of the rank reversal phenomenon in the analytic hierarchy process. J Multi-Crit Decis Anal. 2013; 20:141-55.

117. Curran SS, Tkach W, Overstreet RM. A new species of Homalometron (Digenea: Apocreadiidae) from fishes in the northern Gulf of Mexico. J Parasitol. 2013;99:93-101.

\section{Submit your next manuscript to BioMed Central and we will help you at every step:}

- We accept pre-submission inquiries

- Our selector tool helps you to find the most relevant journal

- We provide round the clock customer support

- Convenient online submission

- Thorough peer review

- Inclusion in PubMed and all major indexing services

- Maximum visibility for your research

Submit your manuscript at www.biomedcentral.com/submit
) Biomed Central 